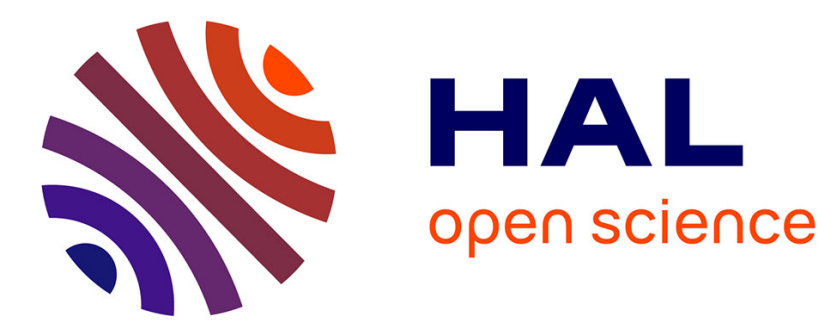

\title{
Some uses of mischmetall in organic synthesis
}

\author{
Marie-Isabelle Lannou, Florence Hélion, Jean-Louis Namy
}

\section{To cite this version:}

Marie-Isabelle Lannou, Florence Hélion, Jean-Louis Namy. Some uses of mischmetall in organic synthesis. Tetrahedron, 2003, 59 (52), pp.10551-10565. 10.1016/j.tet.2003.07.017 . hal-02371191

\section{HAL Id: hal-02371191 \\ https://hal.science/hal-02371191}

Submitted on 5 Oct 2021

HAL is a multi-disciplinary open access archive for the deposit and dissemination of scientific research documents, whether they are published or not. The documents may come from teaching and research institutions in France or abroad, or from public or private research centers.
L'archive ouverte pluridisciplinaire HAL, est destinée au dépôt et à la diffusion de documents scientifiques de niveau recherche, publiés ou non, émanant des établissements d'enseignement et de recherche français ou étrangers, des laboratoires publics ou privés. 


\title{
Some uses of mischmetall in organic synthesis
}

\author{
Marie-Isabelle Lannou, Florence Hélion and Jean-Louis Namy* \\ Laboratoire de Catalyse Moléculaire, associé au CNRS, ICMO, Bat 420, Université Paris-Sud, 91405, Orsay, France.
}

\begin{abstract}
Mischmetall, an alloy of the light lanthanides, has been used in a variety of organic reactions, either as a coreductant in samarium(II)-mediated reactions (Barbier and Grignard-type reactions, pinacolic coupling reactions) or as the promoter of Reformatsky-type reactions. It has been also employed as the starting material for easy syntheses of lanthanide trihalides, the reactivity of which has been explored in Imamoto and Luche-Fukuzawa reactions and in Mukaiyama aldol reactions.
\end{abstract}

\section{Introduction}

The use of rare earth compounds in organic chemistry has grown considerably during the past 20 years. Mainly samarium, cerium, lanthanum, ytterbium, neodymium, dysprosium, lutetium, scandium and yttrium metals and derivatives have been studied. These elements clearly differ in terms of reactivity. For instance, samarium(II) compounds can be used as powerful reductants, whereas, cerium(IV) ones are strong oxidants, some scandium and ytterbium(III) derivatives are very efficient catalysts in a variety of reactions and chemistry of lanthanum metal shows special features. However, we thought that in many reactions, a mixture of lanthanide could be used instead of individual element without significant change in results. This should reduce the cost of reactions since, separation of the elements remains an expensive process. Mischmetall is one of the main sorts of mixed rare earths. It is a well known alloy produced by fused chloride electrolysis of the light lanthanide elements. It comes from a lanthanide ore called bastnaesite (a fluorocarbonate). It constitutes over $90 \%$ of the rare earth metal consumed for steelmaking. The relative concentration of the four light lanthanide elements and of the 'heavies' can vary depending on the origin of the ores. The usual mischmetall contains $48-50 \% \mathrm{Ce}, 32-34 \% \mathrm{La}$, $13-14 \% \mathrm{Nd}, 4-5 \% \mathrm{Pr}$ and $1.5 \%$ other rare earth metals. It is at least 10 times cheaper than cerium. Mischmetall is commercially available as ingots which are easily powered with a rasp (caution! see Section 4). After scraping, it can be stored in a Schlenck tube under argon for several weeks. This is impossible with most of the pure metal powders (especially cerium and lanthanum), the surface of

Keywords: mischmetall; samarium; lanthanide; catalysis; organic reactions.

* Corresponding author. Fax: +33-1-69-15-4690;

e-mail: jelonamy@icmo.u-psud.fr which is rapidly covered with an oxide layer. Here we report some interesting uses of mischmetall in organic synthesis.

\section{Results and discussion}

\subsection{Mischmetall as a coreductant in samarium(II) catalysed reactions}

Since its introduction in synthetic organic chemistry in 1977, ${ }^{1}$ samarium diiodide has become one of the most popular reagents. However, its cost could be considered as a major drawback, potentially limiting the development of its chemistry. For this reason several attempts have been reported to run reactions with catalytic quantities of $\mathrm{SmI}_{2}$ and an in situ regeneration system for the Sm(II) species. ${ }^{2,3}$ Ideally, a system for in situ regeneration of $\mathrm{SmI}_{2}$ should be: (1) cheaper than samarium metal, (2) able to quickly reduce samarium(III) species into samarium(II) ones, which implies the ability to cleave $\mathrm{Sm}$ (III)-O bonds, (3) unreactive towards organic substrates and (4) simple and usable in a variety of the organic reactions mediated by $\mathrm{SmI}_{2}$. Due to their thermochemical properties (redox properties and strength of the $\mathrm{Ln}-\mathrm{O}$ bonds) and the low reactivity of lanthanide metals (if they are not activated with iodine or mercury salts), ${ }^{4}$ cerium, lanthanum, neodymium or praseodymium fit all the above requirements, except for the first one. Fortunately, the alloy of the light lanthanides known as mischmetall (or cerium mixed metal) is available at a low price. Here we refer to some previously published results and we report on new ones concerning the use of mischmetall as a coreductant in Sm(II) mediated reactions. Considering the percentages of each element, the molecular weight of mischmetall is taken as $140 \mathrm{~g} \mathrm{~mol}^{-1}$. It is denoted below as $\mathrm{Ln}$. 
2.1.1. Catalytic Barbier and Grignard-type allylation and benzylation of ketones and aldehydes. ${ }^{5}$ Catalytic reactions of allylic halides were tested with ketones and aldehydes, either according to a Barbier-type Procedure (Catalytic-BP) or a Grignard-type one (Catalytic-GP), (Scheme 1).

$$
\begin{aligned}
& \text { 1) All-X }+\mathrm{R}^{1 \stackrel{\mathrm{O}}{\Perp}} \mathrm{R}^{2}
\end{aligned}
$$

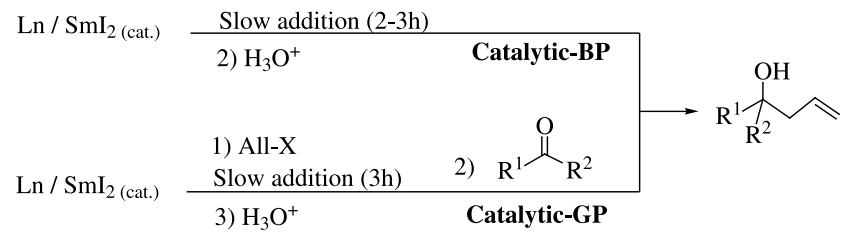

Scheme 1.

In catalytic-BP, yields of tertiary alcohols were close to those obtained under stoichiometric conditions. ${ }^{6}$ In catalytic-GP, tertiary alcohols were obtained in moderate $(\mathrm{X}=\mathrm{I})$ to good yield $(\mathrm{X}=\mathrm{Br})$. In contrast, the sequential procedure cannot be used with samarium diiodide in stoichiometric amount, since the dienes arising from a Wurtz coupling are the only detected products. ${ }^{7}$

We proposed three catalytic schemes (Fig. 1). In all cases
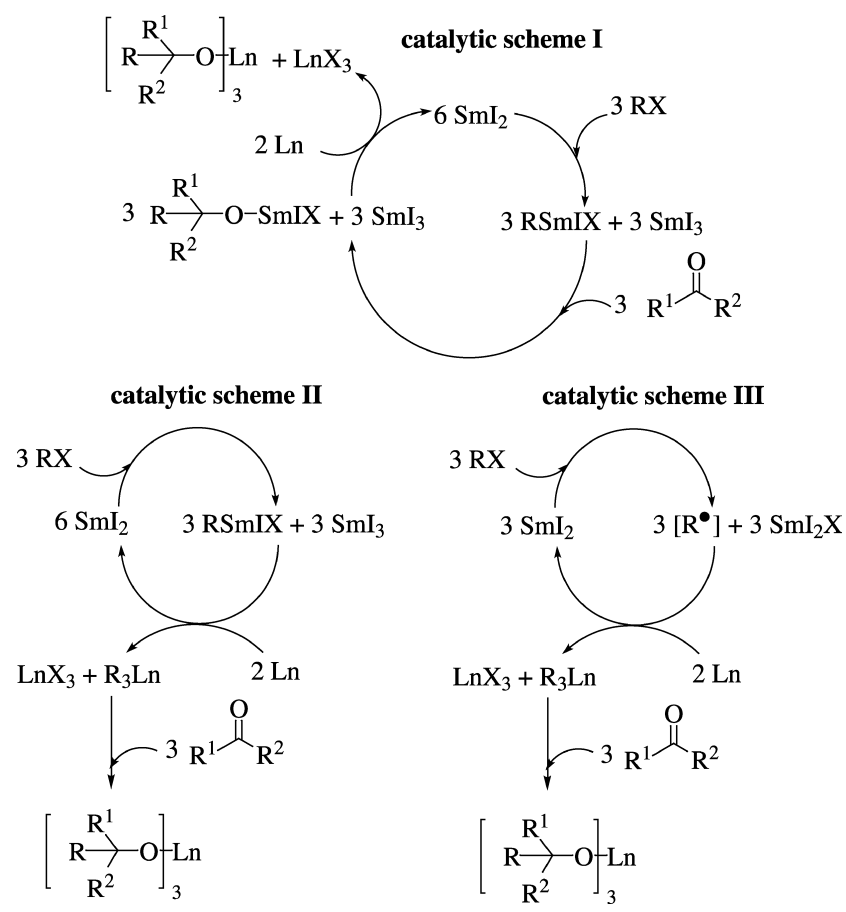

Figure 1. the reaction should occur through formation of organometallic species.

In the catalytic scheme I, an organosamarium compound, $\mathrm{RSmIX}$ (or $\mathrm{RSmX}_{2}$ or $\mathrm{RSmI}_{2}$ ) is formed first. Its addition to a carbonyl compound gives a samarium alkoxide. This in turn, through a reduction-transmetallation process with Ln, provides another lanthanide alkoxide, with the regeneration of $\mathrm{SmI}_{2}$ (or $\mathrm{SmX}_{2}$ ). In the catalytic scheme II, the initially formed RSmIX reacts with Ln to give another organometallic compound $\left(\mathrm{LnR}_{3} ; \mathrm{Ln} \neq \mathrm{Sm}\right)$ through a reductiontransmetallation process, with the regeneration of $\mathrm{SmI}_{2}$. This organolanthanoid compound then adds to the carbonyl compound to furnish an alkoxide. Alternatively, reduction of the initially produced radicals (from a reaction between organic halide and $\mathrm{SmI}_{2}$ ) with $\mathrm{Ln}$ instead of $\mathrm{Sm}(\mathrm{II})$ could give an organometallic compound $\left(\mathrm{R}_{3} \mathrm{Ln}\right)$ directly, $\mathrm{SmI}_{2} \mathrm{X}$ being concomitantly reduced with $\mathrm{Ln}$ into $\mathrm{SmI}_{2}$. This catalytic scheme III (Fig. 1) should not require formation of an organosamarium compound. However, it can be seen as a variant of catalytic scheme II since it also implies a reaction between $\mathrm{R}_{3} \mathrm{Ln}(\mathrm{Ln} \neq \mathrm{Sm})$ and a carbonyl compound.

In catalytic-BP, all three mechanisms are possible, whereas, in catalytic-GP the catalytic scheme I is not possible, as it is known that organosamarium compounds are unstable. On the other hand, the success of this procedure would agree well with the catalytic schemes II or III which imply formation of $\mathrm{R}_{3} \mathrm{Ln}, \mathrm{R}_{2} \mathrm{LnX}$ or $\mathrm{RLnX}_{2}$ ( $\mathrm{Ln}$ other than $\mathrm{Sm}$ ).

As the main components of mischmetall are cerium, lanthanum and neodymium they were tested in both procedures in place of mischmetall under similar experimental conditions. It was found that cerium and lanthanum were both efficient coreductants in these reactions, as well in Catalytic-BP and Catalytic-GP. The results, obtained either with $\mathrm{Ce}, \mathrm{La}$ or $\mathrm{Nd}$ were close to those described with mischmetall. However, the alloy is much cheaper than cerium, lanthanum or neodymium, and moreover is less prone to oxidation. All this is in favour of the use of mischmetall instead of separated lanthanide metals.

Interestingly, a simpler experimental procedure starting from a mixture of samarium metal and mischmetall could be used as depicted below (Scheme 2), while, a sequential procedure also gave excellent results. Thus, it had been demonstrated that a stable organometallic compound was also formed under these experimental conditions (Scheme 3). In both cases the product was obtained in excellent yield.

Presumably, in situ formation of samarium diiodide occurs

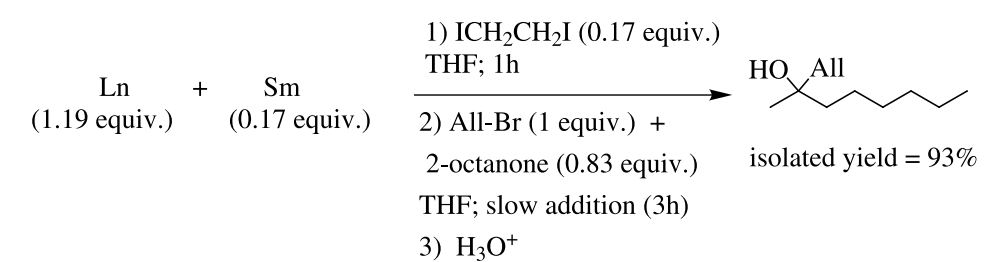




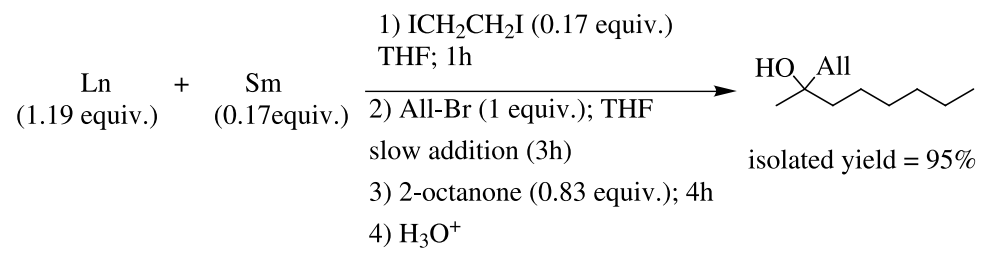

Scheme 3.

under these conditions. In addition, diiodoethane might activate mischmetall, thus facilitating the catalytic process (reduction-transmetallation of RSmIX - see catalytic scheme II, or reduction of radicals-see catalytic scheme III, Figure 1).

\subsubsection{Catalytic Barbier and Grignard-type reactions of} esters and lactones. We first studied reactions of lactones with activated halides (allyl iodide, allyl bromide and benzyl bromide) mediated by the mischmetall/SmI 2 (cat.) system using a Catalytic-BP or a Catalytic-GP and readily observed the formation of diols. Some results are presented in Table $1 .^{8}$ Yields in diols were good or excellent. Nevertheless, the yields were slightly better with the Catalytic-BP than with the Catalytic-GP. In the absence of samarium diiodide the starting materials were recovered unchanged.

Next, we examined the reactions of less active alkyl halides. In stoichiometric conditions, Barbier-type reactions involving lactones or esters and alkyl halides yield the expected diols in the presence of small amounts of nickel diiodide $\left(1 \mathrm{~mol} \%\right.$ with respect to $\left.\mathrm{SmI}_{2}\right) .{ }^{9}$ This experimental process can be termed as $\mathrm{NiI}_{2}$-Catalysed Barbier Procedure (BP/NiI ${ }_{2 \text { (cat.) }}$ ). Therefore, the mischmetall/ $\left[\mathrm{SmI}_{2} / \mathrm{NiI}_{2 \text { (cat'.) }}\right]_{\text {(cat.) }}$ system was used in a Catalytic Barbier Procedure catalysed with $\mathrm{NiI}_{2}$ (Catalytic-BP/NiI 2 (cat.) and compared to the mischmetall/ $\mathrm{SmI}_{2 \text { (cat.) }}$ system in a catalytic Barbier procedure (Catalytic-BP). Some results are presented in Table $2 .^{8}$

We checked that both mischmetall alone and mischmetall in the presence of nickel diiodide (without $\mathrm{SmI}_{2}$ ), were unreactive in the reactions indicated above. The results obtained with the five or six-membered-ring lactones (entries 1,2 ) were in good agreement with the expectations since good yields in diols were obtained with nickel diiodide, whereas, in the absence of this catalyst, starting materials were recovered unchanged. Thus, this 'double-stage catalysis' is efficient in those cases. More

Table 1. Catalytic reactions of activated halides mediated by the mischmetall/ $/ \mathrm{SmI}_{2}$ system

$$
\begin{aligned}
& \text { 1) } \mathrm{R}^{1} \mathrm{Br}+\mathrm{R}^{2} \stackrel{\text { 省 }}{\mathrm{OR}^{3}} \\
& \mathrm{Ln} / \mathrm{SmI}_{2} \text { (cat) } \frac{\text { Slow addition }(2.5 \mathrm{~h})}{\text { 2) } \mathrm{H}_{3} \mathrm{O}^{+}} \text {Catalytic-BP }
\end{aligned}
$$

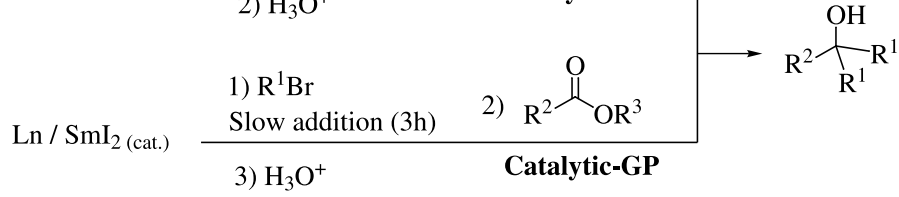

$$
\begin{aligned}
& \text { 1) } \mathrm{R}^{1} \mathrm{Br}+\mathrm{O}_{\mathrm{O}} \\
& \begin{array}{lll}
\mathrm{Ln} / \mathrm{SmI}_{2} \text { (cat.) } & \text { Slow addition (2.5h) } & \\
\cline { 3 - 3 } & \text { 2) } \mathrm{H}_{3} \mathrm{O}^{+} & \text {Catalytic-BP }
\end{array}
\end{aligned}
$$

\begin{tabular}{|c|c|c|c|c|}
\hline \multirow[t]{2}{*}{ Entry } & \multirow[t]{2}{*}{$\mathrm{R}^{1} \mathrm{Br}$} & \multirow[t]{2}{*}{ Ester or lactone } & \multicolumn{2}{|c|}{ Isolated yields (\%) } \\
\hline & & & Catalytic-BP & Catalytic-GP \\
\hline 1 & All-I & Ethyl benzoate & 74 & 54 \\
\hline 2 & All-Br & Ethyl benzoate & 68 & 73 \\
\hline 3 & $\mathrm{Bn}-\mathrm{Br}$ & Ethyl benzoate & 71 & 55 \\
\hline 4 & All-I & Ethyl $i$-butyrate & 60 & 52 \\
\hline 5 & All-Br & Ethyl $i$-butyrate & 64 & 50 \\
\hline 6 & $\mathrm{Bn}-\mathrm{Br}$ & Ethyl $i$-butyrate & 84 & 73 \\
\hline 7 & $\mathrm{Bn}-\mathrm{Br}$ & $\beta$-Propiolactone & 56 & 71 \\
\hline 8 & $\mathrm{Bn}-\mathrm{Br}$ & $\gamma$-Butyrolactone & 77 & 50 \\
\hline
\end{tabular}

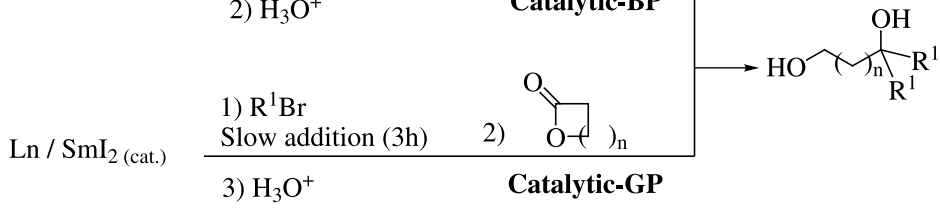

\footnotetext{
${ }^{a}$ For experimental details, see Ref. 8.
} 
Table 2. Catalytic Barbier-type reactions of lactones or esters with iodoheptane

$$
\begin{aligned}
& \text { Iodoheptane + } \\
& \begin{array}{l}
\text { 1) } \mathrm{Ln} / \mathrm{SmI} \text { (cat.) }_{\text {2) } \mathrm{H}_{3} \mathrm{O}^{+}} \text {2) } \mathrm{H}_{3} \mathrm{O}^{+} \\
\text {1) } \mathrm{Ln} / \mathrm{SmI}_{2} \text { (cat.) }
\end{array}
\end{aligned}
$$

\begin{tabular}{|c|c|c|c|}
\hline \multirow[t]{2}{*}{ Entry } & \multirow[t]{2}{*}{ Ester or lactone } & \multicolumn{2}{|c|}{ Isolated yields (\%) } \\
\hline & & Catalytic-BP ${ }^{\mathrm{a}}$ & Catalytic-BP/NiI ${ }_{2 \text { (cat.) }}{ }^{a}$ \\
\hline 2 & $\delta$-Valerolactone & 0 & 66 \\
\hline 3 & $\varepsilon$-Caprolactone & 91 & 68 \\
\hline 4 & Ethylbenzoate & 74 & 78 \\
\hline 5 & $t$-Butylacetate & 70 & 72 \\
\hline 6 & Ethyl-i-butyrate & 76 & 81 \\
\hline
\end{tabular}

${ }^{\text {a }}$ For experimental details, see Ref. 8.

$$
\begin{aligned}
& \text { 1) } \mathrm{Ph} \stackrel{\mathrm{O}}{\mathrm{N}}
\end{aligned}
$$

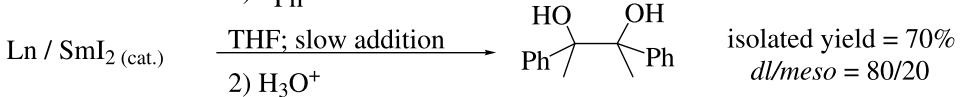

Scheme 4 .

unexpectedly, the diol was obtained with $\varepsilon$-caprolactone in excellent yield in the absence of nickel diiodide (entry 3 ). It was thus anticipated that esters should behave like this unstrained lactone. This was confirmed: good yields in tertiary alcohols were obtained in both procedures (entries 4-6). Thus, with $\varepsilon$-caprolactone and esters the catalytic Barbier procedure does not require the presence of nickel diiodide while the stoichiometric Barbier procedure demands it. This shows that the mischmetall/ $\mathrm{SmI}_{2 \text { (cat.) }}$ system can be more reactive than stoichiometric samarium diiodide. Some hypotheses are proposed in Ref. 8 to explain these results.

2.1.3. Pinacol coupling reactions. The pinacol coupling of acetophenone can be readily performed using $\mathrm{SmI}_{2}$ as a catalyst and mischmetall as a coreductant (Scheme 4). In contrast to the previously reported procedure, which uses magnesium as a coreductant, there is no need to add trimethylsilyl chloride to cleave the $\mathrm{Sm}(\mathrm{III})-\mathrm{O}$ bonds. ${ }^{3}$ The pinacol coupling product is obtained in good isolated yield. The $d l / m e s o$ ratio $(80: 20)$ is the same as that measured when the reaction is performed under stoichiometric conditions $(79: 21){ }^{10}$ This result is in good agreement with a pinacolisation mediated by $\mathrm{SmI}_{2}$ leading to a samarium(III) pinacolate, the reduction of which by mischmetall regenerates $\mathrm{SmI}_{2}$. Without samarium diiodide, no reaction occurs.

This first result was interesting. However, the method is limited to aromatic ketones. ${ }^{11}$ Samarium dibromide is a more powerful reagent in pinacol coupling. ${ }^{12}$ This led us to examine the possibility to perform catalytic pinacol coupling reactions using this reagent and mischmetall as a coreductant.

Before studying catalytic pinacol coupling, we first tried to find an easy and reliable method of preparation of samarium dibromide. This compound can be prepared directly from samarium metal and 1,2-dibromoethane in THF. ${ }^{12}$ However, the latter reaction usually needs a long induction time and small amounts of diiodoethane have to be added to ensure reproducible results. To overcome this drawback, we attempted to use 1,1,2,2-tetrabromoethane instead of 1,2dibromoethane. Mixing samarium with 1 equiv. of $\mathrm{C}_{2} \mathrm{H}_{2} \mathrm{Br}_{4}$ in THF resulted in a fast exothermic reaction, evolution of a gas, and disappearance of samarium metal. A creamcoloured solid was formed which failed for the coupling of 5-nonanone into diol. It was identified as being samarium tribromide. ${ }^{13}$ With half an equivalent of 1,1,2,2-tetrabromoethane, a gas (acetylene) was also produced and a dark blue solid, which was slightly soluble in THF, was obtained. Its reaction with 5-nonanone furnished the expected diol in $87 \%$ isolated yield. These properties are in agreement with those of $\mathrm{SmBr}_{2}$. Scheme 5 sums up the results.

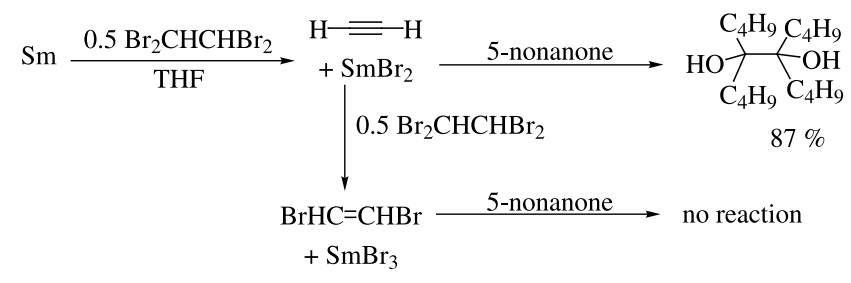

Scheme 5. 
Table 3. Catalytic pinacolizations using $\mathrm{SmBr}_{2}$ and mischmetall

$$
\begin{aligned}
& \underset{(\mathbf{x} \text { mmol })}{\operatorname{mischmetall}}+\underset{(\mathbf{y} \mathrm{mmol})}{\mathrm{Sm}} \frac{1) \mathrm{Br}_{2} \mathrm{CHCHBr}_{2}(\mathbf{z} \mathrm{mmol}) ; \mathrm{THF} ; 2 \mathrm{~h}}{2) \text { carbonyl compound (4 mmol); THF }} \text { pinacol } \\
& \text { slow (14h) or fast addition }
\end{aligned}
$$

\begin{tabular}{|c|c|c|c|c|c|}
\hline Entry & Carbonyl compounds & $x / y / z$ & Conditions & Isolated yields $(\%)^{\mathrm{a}}$ & dl/meso \\
\hline 1 & Cyclobutanone & $5: 1.4: 0.7$ & Slow & 1: 66 & \\
\hline 2 & Cyclohexanone & $5: 1.4: 0.7$ & Slow & 55 & \\
\hline 3 & Cyclooctanone & $5: 1.4: 0.7$ & Slow & 69 & \\
\hline 4 & Benzaldehyde & $5: 1.4: 0.7$ & Slow & 62 & $57: 43$ \\
\hline 5 & Pivalaldehyde & $5: 1.4: 0.7$ & Slow & 2: 63 & 100:0 \\
\hline 6 & 2-Octanone & $5: 1.4: 0.7$ & Slow & 72 & $50: 50$ \\
\hline 7 & 3-Octanone & $5: 0.7: 1.4$ & Fast & 54 & $50: 50$ \\
\hline 8 & 5-Nonanone & $5: 0.7: 1.4$ & Fast & 68 & \\
\hline 9 & Acetophenone & $5: 0.7: 1.4$ & Fast & 72 & $80: 20$ \\
\hline 10 & 1,3-Dibenzoylpropane ${ }^{\mathrm{b}}$ & $5: 0.7: 1.4$ & Fast & 3: $70^{\mathrm{c}}$ & \\
\hline
\end{tabular}

${ }^{\text {a }}$ For experimental details, see Section 4.

b Carbonyl compound: 2 mmol.

c cis 1,2-Diphenylcyclopentan-1,2-diol.

In $\mathrm{SmI}_{2}$ catalytic Barbier-type reaction, we had observed that a simple experimental procedure, which starts from a mixture of samarium metal and mischmetall treated by 1,2diiodoethane, gave excellent results (see above). Here we applied this methodology, changing the diiodide for the tetrabromide. Some results are shown in Table 3.

This procedure involving a mixture of Sm and mischmetall has allowed us to isolate pinacols in moderate to good yields. In some cases a slow addition of the carbonyl compound was necessary in order to allow regeneration of $\mathrm{Sm}$ (II) species thus preventing formation of by-products. The quantities of each reagent (mischmetall, samarium, tetrabromoethane) have been optimised according to the procedure (fast or slow addition of the carbonyl compounds). We observed in some cases that an excess of tetrabromoethane, with respect to samarium, improved the yields in pinacol (entries 7-10), probably in facilitating the regeneration of samarium dibromide (more bromide ions are available). In the absence of samarium, the diols were not obtained, either the carbonyl compound was recovered or a complex mixture of products was formed. Without tetrabromoethane, no reaction took place.

The following catalytic scheme can be proposed. In contrast to the previously reported $\mathrm{SmI}_{2}$-catalytic pinacolization ${ }^{3}$ there is no need to use TMSCl together with a coreductant since cerium and lanthanum (the main components of mischmetall) are both able to cleave the $\mathrm{Sm}-\mathrm{O}$ bond and to reduce $\mathrm{Sm}$ (III) species into $\mathrm{Sm}$ (II) ones, (Scheme 6).

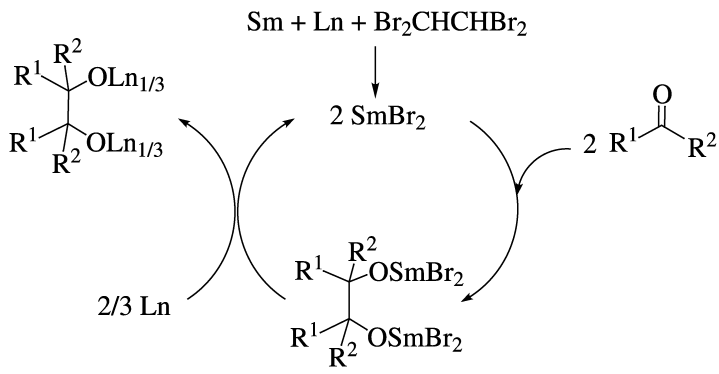

Scheme 6.
2.1.4. Reformatsky-type reactions. Since the pioneering works of Kagan et al. in the field of samarium diiodide mediated reactions, ${ }^{7}$ many reports have demonstrated the crucial role of this reagent in Reformatsky-type reactions, as well in intermolecular reactions using chiral auxiliaries ${ }^{14}$ than in intramolecular ring-closure reactions. ${ }^{15,16}$ Nevertheless, no reaction using samarium diiodide in catalytic amounts has been reported so far.

Since our previous work using catalytic amounts of samarium diiodide in Barbier and Grignard-type reactions were very promising, ${ }^{5}$ Reformatsky-type reactions have been performed using the mischmetal/SmI $\mathrm{Sm}_{2}$ catalyticsystem. Reactants were added simultaneously following a Barbier-type procedure. As expected, our system is an efficient promoter for Reformatsky-type reactions using a Barbier-type procedure. The expected $\beta$-hydroxyesters were obtained in medium to good yields, the results are presented in Table 4 .

The electrophile/ $\alpha$-bromoester ratio had to be established first. Thus, when a 1:1 ratio was used, yields were very low due to side-reactions, mainly debromination and autocondensation reactions. With ethyl 2-bromobutyrate and tert-butyl 2-bromoacetate, it was found that a 1:2 ratio allows the formation of the $\beta$-hydroxyesters with satisfactory yields. Besides, 3 equiv. of methyl 2-bromoacetate (with respect to the ketone) were required for the reaction to proceed with acceptable yields since it is more susceptible to develop side-reactions than other $\alpha$-bromoesters. ${ }^{17}$ It is known that $\alpha$-bromoesters are subject to side-reactions such as reduction and autocondensation. They can react with tetrahydrofuran either by a radical pathway or via an anionic pathway (Scheme 7) to give the reduced product $\mathbf{A}$, or the autocondensation product $\mathbf{B}$ by reaction with another $\alpha$-bromoester (Scheme 8). ${ }^{18}$ Methyl 2-bromoacetate and tert-butyl 2-bromoacetate are subject to debromination reaction (Scheme 7) rather than autocondensation, whereas, for ethyl 2-bromobutyrate, the autocondensation product has been observed and fully characterised (IR, ${ }^{1} \mathrm{H}$ and ${ }^{13} \mathrm{C}$ NMR). 
Table 4. Reformatsky-type reactions mediated by the mischmetall/ $\mathrm{SmI}_{2 \text { (cat.) }}$ system

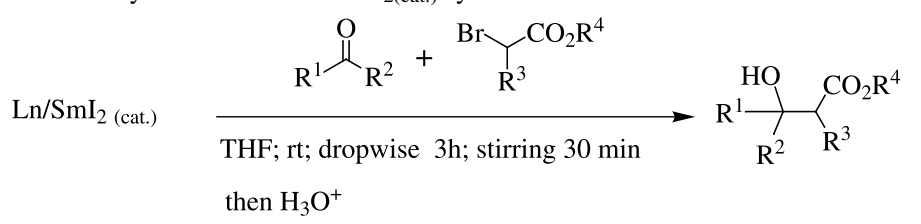

\begin{tabular}{llll}
\hline Entry & \multicolumn{1}{c}{ Electrophile } & \multicolumn{1}{c}{$\alpha$-Bromoester } & Ratio $^{\mathrm{a}}$ \\
1 & 4-Phenyl-butan-2-one & Methyl 2-bromoacetate & $1: 2.9$ \\
2 & 4-Phenyl-butan-2-one & tert-Butyl 2-bromoacetate & $1: 2$ \\
3 & 4-tert-Butyl-cyclohexanone & Methyl 2-bromoacetate & $1: 2.9$ \\
4 & 4-tert-Butyl-cyclohexanone & tert-Butyl 2-bromoacetate & $1: 2$ \\
5 & Acetophenone & Methyl 2-bromoacetate & $1: 2.9$ \\
6 & Acetophenone & tert-Butyl 2-bromoacetate & $1: 2$ \\
7 & Cyclohexanone & Ethyl 2-bromobutyrate & $1: 2$ \\
8 & Cyclohexanone & Ethyl 2-bromobutyrate & $1: 2$ \\
9 & 2-Indanone & Ethyl 2-bromobutyrate & $1: 2$ \\
10 & Benzaldehyde & Methyl 2-bromoacetate & $51^{\text {d }}$ \\
11 & Octanal & Methyl 2-bromoacetate & 92 \\
\hline
\end{tabular}

\footnotetext{
${ }^{a}$ Electrophile/ $\alpha$-bromoester.

b For experimental details, see Section 4.

c cis/trans $=60: 40$.

d cis/trans $=80: 20$.

e Fast addition of the reactants.
}

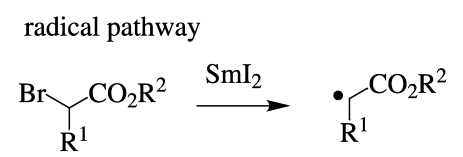<smiles>[R]C(=O)CCC1CCCO1</smiles>

anionic pathway

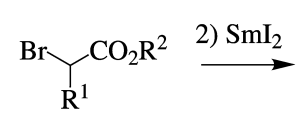<smiles>[R]C(=[R])O[Na]</smiles><smiles>C1CCOC1</smiles>

Scheme 7.

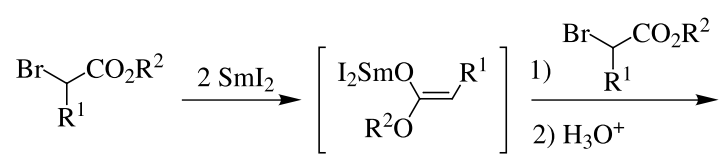<smiles>[R]CC(=O)C([R])C(=O)O[R20]</smiles>

Scheme 8.

When using aldehydes as electrophiles (entries 10 and 11), complex mixtures are obtained. Thus, only trace amounts of desired products are detected by ${ }^{1} \mathrm{H} \mathrm{NMR}$, cyclotrimerisation of aldehydes being faster than the formation of the $\beta$-hydroxyester.

Reformatsky-type reactions also seemed to be an interesting target for our system since it has been previously observed that stable organolanthanides species have been obtained with allylic and benzylic bromides (see above). In a similar way, we tried to obtain stable enolates. The reaction was carried out in two stages: addition of the $\alpha$-bromoester to the mischmetall/ $/ \mathrm{SmI}_{2 \text { (cat.) }}$ system, followed by quenching with an electrophile. Many reactions have been performed between ethyl 2-bromobutyrate and cyclohexanone (Scheme 9), unfortunately, always leading either to the starting material (temperatures lower than $-50^{\circ} \mathrm{C}$ ) or to $\beta$-ketoester at higher temperatures since the autocondensation reaction is strongly predominant.

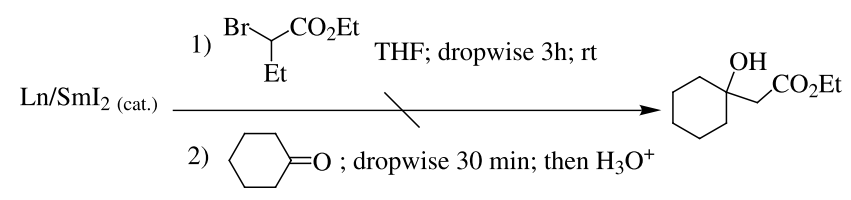

Scheme 9.

The formation of the autocondensation product has already been studied in the reaction of ethyl 2-bromoacetate with stoichiometric samarium diiodide by Utimoto et al., ${ }^{18}$ who have proved that an unreactive intermediate is produced at a temperature above $-50^{\circ} \mathrm{C}$.

\subsection{Reformatsky-type reaction mediated by activated mischmetall}

More than one hundred years after its discovery, the Reformatsky-type reaction is still widely studied. In the last decades it has been described to be promoted by several 
Table 5. Some additives of mischmetall in Reformatsky-type reactions

$$
\text { Ln + additive (cat) }
$$

\begin{tabular}{|c|c|c|}
\hline Entry & Additive & Isolated yield $(\%)^{\mathrm{a}}$ \\
\hline 1 & None & 0 \\
\hline 2 & Diiodoethane & $65^{\mathrm{b}}$ \\
\hline 3 & Diiodoethane & $40^{\mathrm{c}}$ \\
\hline 4 & Diiodoethane & 65 \\
\hline 5 & Dibromoethane & 53 \\
\hline 6 & Iodine & 79 \\
\hline
\end{tabular}

${ }^{a}$ For experimental details, see Section 4.

b Reactants were added dropwise in $3 \mathrm{~h}$; mischmetall/diiodoethane $=1: 1$.

${ }^{c}$ Idem; ketone/ $\alpha$-bromoester $=1: 1$.

activated or non-activated metals among these: zinc, ${ }^{19}$ indium, ${ }^{20}$ germanium ${ }^{21}$ or cerium. ${ }^{22}$

Pioneering works of Imamoto et al. in this field ${ }^{22}$ have revealed the role of the activation of cerium metal in the Reformatsky-type reaction. Cerium was activated either by amalgamation or by catalytic amounts of mercury(II) chloride. Some attempts have been previously reported concerning the use of mischmetall in Grignard and in Reformatsky reactions. ${ }^{23} \mathrm{We}$ then decided to investigate further the reactivity of mischmetall in the Reformatskytype reaction. At first, activated mischmetall was tested in the reaction between ethyl 2-bromo-butyrate and cyclohexanone. The results are presented in Table 5.

Mischmetall alone is not capable of promoting the Reformatsky-type reaction (reactants are fully recovered), but the addition of catalytic amounts of iodine, dibromoethane or diiodoethane to the alloy allows the formation of the desired $\beta$-hydroxyesters. The best result was obtained with iodine, but results were more reproducible with diiodoethane, for that reason, the system mischmetall/diiodoethane $_{\text {(cat.) }}$ has been further investigated and the results are listed in Table 6.

As a conclusion, mischmetall is an efficient coreductant for samarium diiodide catalysed Reformatsky-type reactions. Nevertheless, the process requires a dropwise addition of the reactants. The limitations of this method are that stable enolates cannot be obtained and the reaction does not work with aldehydes as electrophiles due to their ability to form cyclotrimers in the presence of mischmetall. On the other hand, activated mischmetall is also a good promoter for Reformatsky-type reactions. Moreover, activation by organic halides is a very simple procedure. The reaction is less sensitive to air than with samarium diiodide and yields are good in most of the cases even if slightly lower than with samarium diiodide. However, dropwise addition of the reactants is not necessary in that case. As described above, the reaction does not work when aldehydes are used as electrophiles.

To conclude, it seems obvious that there is no need to work with cerium metal activated by mercury ${ }^{22}$ since mischmetall seems to show a high reactivity in Reformatsky-type reactions and the use of iodine or diiodoethane is much more convenient than amalgamation.

\subsection{Preparations and uses of anhydrous mischmetall halides}

2.3.1. Preparations of anhydrous lanthanide trihalides. Classical methods for the preparation of anhydrous rare earth trihalides $\left(\mathrm{LnX}_{3}, \mathrm{X}=\mathrm{Cl}\right.$ or $\left.\mathrm{Br}\right)$ involve reaction of lanthanide oxides with hydroacids in water, followed by drying with $\mathrm{NH}_{4} \mathrm{Cl}$, or trimethyl orthoformate or thionyl chloride. Some years ago, Deacon et al. ${ }^{24}$ reported the preparation of anhydrous lanthanide trichlorides from metal

Table 6. Use of mischmetall in Reformatsky-type reactions

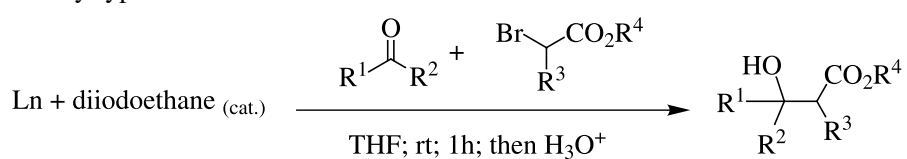

\begin{tabular}{lll}
\hline Entry & \multicolumn{1}{c}{ Electrophile } & \multicolumn{1}{c}{$\alpha$-Bromoester } \\
\hline 1 & 4-Phenyl-butan-2-one & Methyl 2-bromoacetate \\
2 & 4-Phenyl-butan-2-one & tert-Butyl 2-bromoacetate \\
3 & 4-tert-Butylcyclohexanone & Methyl 2-bromoacetate \\
4 & 4-tert-Butylcyclohexanone & tert-Butyl 2-bromoacetate \\
5 & Acetophenone & Methyl 2-bromoacetate \\
6 & Acetophenone & tert-Butyl 2-bromoacetate \\
\hline
\end{tabular}

${ }^{a}$ For experimental details, see Section 4.

b cis/trans $=35: 65$.

c cis/trans $=65: 35$. 


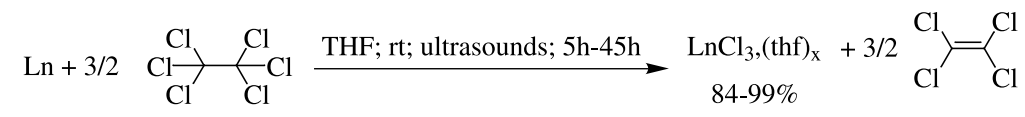

$$
\begin{aligned}
& \mathrm{Ln}=\mathrm{La}, \mathrm{Nd}, \mathrm{Sm}, \mathrm{Gd}, \mathrm{Yb}, \mathrm{Er}
\end{aligned}
$$

Scheme 10.

Table 7. Preparation of lanthanide trichlorides

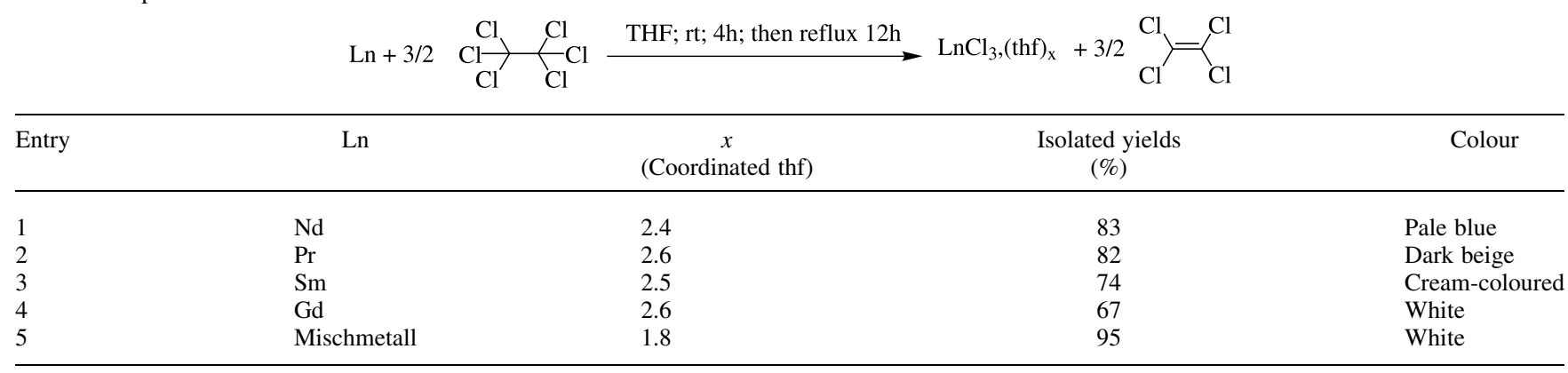

and hexachloroethane in THF under ultrasonic activation (Scheme 10).

We have performed a similar reaction with mischmetall powder. In this case, ultrasonic activation was not required. Considering this result we wondered whether pure metals could furnish anhydrous lanthanide chlorides in a similar fashion provided powder was freshly prepared by scraping of ingots. We tested samarium, neodymium, praseodymium and gadolinium metals and were pleased to observe the expected reaction with hexachloroethane. The results are presented in Table 7.

Titrations were performed as previously described. ${ }^{13}$ Yields in complexes were good to excellent, and the number of thf molecules coordinated to the metal was in accordance with the results found by Deacon et al.

Lanthanoid tribromides are generally synthesized from lanthanide oxides and hydrobromic acid in water, then subsequently dried with $\mathrm{NH}_{4} \mathrm{Cl}$. The main drawback is their high tendency to undergo hydrolysis. Previous work showed that anhydrous samarium dibromide can be prepared from dibromoethane and samarium metal in THF. ${ }^{12}$ Thus, it has been assumed that trivalent lanthanide bromides could be prepared in the same manner. However, the reaction usually needs a long induction time and small amounts of diiodoethane must be added to ensure reproducible results. To overcome this drawback, we attempted to use 1,1,2,2-

Table 8. Preparation of lanthanide tribromides

\begin{tabular}{|c|c|c|c|c|}
\hline & $\mathrm{Br}_{\mathrm{B}} \mathrm{B}$ & THF; rt; 4h; the & $\stackrel{\text { reflux } 12 \mathrm{~h}}{\longrightarrow}$ & $\mathrm{Br}_{3},(\text { thf })_{\mathrm{x}}$ \\
\hline Entry & $\mathrm{Ln}$ & $x$ (Coordinated thf) & $\begin{array}{l}\text { Isolated yields } \\
(\%)\end{array}$ & Colour \\
\hline 1 & $\mathrm{Nd}$ & 4 & 83 & Beige \\
\hline 2 & $\operatorname{Pr}$ & 3.5 & 85 & Beige \\
\hline 3 & $\mathrm{Sm}$ & 4 & 77 & Pale green \\
\hline 4 & $\mathrm{Gd}$ & 4 & 86 & Grey \\
\hline 5 & Mischmetall & 2.6 & 89 & Brown \\
\hline
\end{tabular}

tetrabromoethane instead of 1,2-dibromoethane, the results are presented in Table 8.

Yields in trihalides are good and this method gives a new and simple access to anhydrous lanthanide tribromides. An excess of tetrabromoethane was employed and we observed both the formation of a mixture of $(Z)$ and $(E)-1,2-$ dibromoethene and evolution of a gas which was identified as being acetylene by trapping with aqueous $\mathrm{Cu}\left(\mathrm{NH}_{3}\right)_{2} \mathrm{Cl}$ (brick red cuprous acetylide was formed). Though heating is not absolutely necessary, it was used to make sure that all the metal powder is consumed. It is worth noting that the alloy is a good starting material for the preparation of tribromides since the yield is good and the starting product is cheap. The numbers of thf molecules coordinated to the metals are larger with lanthanide tribromides than with lanthanide trichlorides.

A few preparations of lanthanide triiodides have been reported either requiring large excesses of reagents or drastic conditions. ${ }^{25,26}$ Only samarium and ytterbium triiodides have been easily prepared in two steps from the metal. ${ }^{13}$ This procedure is possible due to their stability in the divalent state. We found a very simple way to prepare trivalent lanthanide iodides starting from freshly scraped metals and diiodoethane in one step. This procedure seems applicable to all lanthanide metals. It is similar to the one reported for samarium diiodide. The use of diiodoethane is a good choice since the formation of ethylene gas displaces the reaction towards the complex formation. The results are presented in Table 9.

The reaction is very vigorous. As a consequence, there is no need for heating the reaction mixture and yields of lanthanide triiodides are good to excellent. Lanthanum triiodide, that is normally prepared in 1,2-dimethoxyethane from lanthanum metal and iodine at reflux for $20 \mathrm{~h},{ }^{26 \mathrm{~b}}$ can be prepared at room temperature in THF (entry 1). It comes out that the number of thf molecules coordinated on the metal increases along with the size of the anion.

As a conclusion, anhydrous lanthanide trihalides have been prepared using a simple and efficient method in one step 
Table 9. Preparation of lanthanide triiodides

\begin{tabular}{|c|c|c|c|c|}
\hline \multicolumn{2}{|c|}{$\operatorname{Ln}+3 / 2$} & THF; rt; $12 \mathrm{~h}$ & $\mathrm{LnI}_{3},(\mathrm{thf})_{\mathrm{x}}$ & $+3 / 2=$ \\
\hline Entry & $\mathrm{Ln}$ & $\begin{array}{c}x \\
\text { (Coordinated thf) }\end{array}$ & $\begin{array}{c}\text { Isolated yields } \\
(\%)\end{array}$ & Colour \\
\hline & $\mathrm{La}$ & 4.4 & 66 & Beige \\
\hline & $\mathrm{Nd}$ & 4 & 88 & Yellow \\
\hline 3 & Pr & 4.3 & 91 & Pale beige \\
\hline & $\mathrm{Sm}$ & 4.2 & 84 & Yellow-green \\
\hline & $\mathrm{Gd}$ & 4 & 89 & Beige \\
\hline & Mischmetall & 4.3 & 79 & Beige \\
\hline
\end{tabular}

from several lanthanide metals. It is worth noting that the preparations of trihalides proceed in a satisfactory way with mischmetall.

Then our aim was to investigate the efficiency of trihalides prepared from the alloy in order to compare their reactivity with those of complexes prepared from pure metals. In the first part, reactions involving stoichiometric amounts of lanthanide trihalides such as Luche-Fukuzawa and Imamoto-type reactions were performed and in the second part, reactions involving catalytic amounts of anhydrous lanthanide trihalides in Mukaiyama aldol-type reactions were investigated.

2.3.2. Anhydrous mischmetall trichloride in LucheFukuzawa-type reductions of $\boldsymbol{\alpha}, \boldsymbol{\beta}$-unsaturated carbonyl compounds. Fukuzawa et al. have described an extended version of the Luche reaction where the use of 'anhydrous' cerium trichloride along with $\mathrm{LiAlH}_{4}$ allows the selective reduction of $\alpha, \beta$-unsaturated carbonyl compounds in the 1,2-positions leading to allylic alcohols. ${ }^{27} \mathrm{We}$ have performed the same reactions using anhydrous lanthanide trichlorides prepared from mischmetall. The results are given in Table 10.

As expected, $\alpha, \beta$-unsaturated carbonyl compounds are easily reduced, but many differences have been observed between the reactivity of the anhydrous $\mathrm{LnCl}_{3}(\text { thf })_{1.8}$ $(\mathrm{Ln}=$ mischmetall) and lanthanide trichlorides used by Fukuzawa. Indeed, a 2:1 stoichiometry $\left(\mathrm{LiAlH}_{4} / \mathrm{CeCl}_{3}\right)$ (with respect to the carbonyl compound) is used by Fukuzawa to reduce selectively an unsaturated ketone in the 1,2 positions. In our case, fully reduced product was observed along with the desired one when using Fukuzawa

Table 10. Mischmetall trichloride in some Luche-Fukuzawa-type reductions

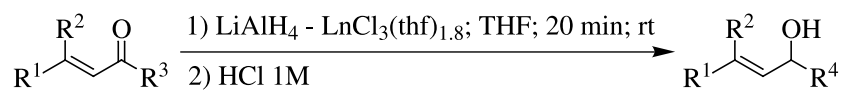

\begin{tabular}{llllll}
\hline Entry & $\mathrm{R}^{1}$ & $\mathrm{R}^{2}$ & \multicolumn{1}{c}{$\mathrm{R}^{3}$} & $\mathrm{R}^{4}$ & Isolated yields (\%) \\
\hline 1 & $\mathrm{Ph}$ & $\mathrm{H}$ & $\mathrm{Me}$ & $\mathrm{Me}$ & 94 \\
2 & $\mathrm{Ph}$ & $\mathrm{H}$ & $\mathrm{H}$ & $\mathrm{H}$ & 94 \\
3 & $\mathrm{Ph}$ & $\mathrm{H}$ & $\mathrm{OH}$ & $\mathrm{H}$ & 68 \\
4 & $\mathrm{Ph}$ & $\mathrm{H}$ & $\mathrm{OC}_{2} \mathrm{H}_{5}$ & $\mathrm{H}$ & 71 \\
3 & $\mathrm{Me}$ & $\mathrm{H}$ & $\mathrm{H}$ & 84
\end{tabular}

stoichiometry. It is then necessary to use a 1:1 stoichiometry for $\mathrm{LiAlH}_{4} / \mathrm{LnCl}_{3}$. Moreover, it was reported that on addition of $\mathrm{LiAlH}_{4}$, a vigorous gas evolution is observed. In our case, no gas evolution occurs. It seems that commercially available lanthanide trichlorides heptahydrates cannot be totally dehydrated even after drying under drastic conditions. 1 or 2 mol equiv. of $\mathrm{LiAlH}_{4}$ are consumed by the remaining water molecules coordinated to the metal. Evans et al. have previously observed the presence of water in cerium trichloride heptahydrate dried by standard procedures such as high vacuum $\left(10^{-3} \mathrm{~mm} \mathrm{Hg}\right)$ : at least one or two molecules of water remain coordinated to the metal. ${ }^{28}$

Anhydrous lanthanide trichlorides are very efficient promoters for extended Luche-type reaction. Expected allylic alcohols are obtained in good to excellent yields, with a complete 1,2-selectivity and the method using anhydrous lanthanide trichlorides and $\mathrm{LiAlH}_{4}$ is less restrictive than typical Luche reactions since $\alpha, \beta$-unsaturated carbonyl compounds such as aldehydes, esters and carboxylic acids can be reduced. Moreover, the anhydrous lanthanide trichloride prepared from mischmetall shows a very good reactivity and selectivity in this reaction.

As a conclusion, there is no need to use a trichloride synthesized from a pure lanthanide metal since the efficiency of complexes prepared from the alloy is very good. Moreover, the reactivity of commercial lanthanides trichlorides is different from that one of our complexes, since lanthanide trichlorides prepared from lanthanide oxides cannot be anhydrous even after drying under drastic conditions. In contrast, our complexes are anhydrous, cheap and their preparation can be carried out easily in one step.

2.3.3. Anhydrous mischmetall trihalides in Imamototype reactions. The chemistry of organocerium(III) reagents has been previously reported by Imamoto et al. ${ }^{22,29}$ Their reactivity towards $\alpha, \beta$-unsaturated aldehydes or ketones shows a strong carbonylophilic character, leading to the selective 1,2-addition on the carbonyl group. Organocerium(III) reagents are formed by reaction of alkyl lithium reagents with lanthanides trihalides.

Some reactions have been performed in order to compare the selectivity of anhydrous mischmetall trihalide-promoted addition of alkyl lithium reagents to $\alpha, \beta$-unsaturated carbonyl compounds with one of the commercially available cerium trichloride. The results are presented in Table 11

Anhydrous mischmetall trihalides $(\mathrm{X}=\mathrm{Cl}, \mathrm{Br}, \mathrm{I})$ exhibit a good reactivity and an excellent diastereoselectivity in 1,2addition of alkyl lithium reagents to $\alpha, \beta$-unsaturated carbonyl compounds. Yields of expected allylic alcohols are excellent except for the reaction of $\beta$-ionone with $n$-BuLi in the presence of $\mathrm{LnI}_{3}$ where a complex mixture is formed (entry 10). In contrast to $\mathrm{CeCl}_{3}$ prepared according to the classical procedure which remain hydrated, with the anhydrous mischmetall trichloride, the 1:1 stoichiometry ( $\left.\mathrm{LnCl}_{3} / n-\mathrm{BuLi}\right)$ is convenient to allow the formation of the expected allylic alcohol since $n$-butyl lithium is directly 
Table 11. Mischmetall trihalides in some Imamoto-type reactions

$$
\mathrm{LnX}_{3},(\text { thf) })_{\mathrm{x}} \stackrel{\text { 1) } n \text {-BuLi (1 equiv.); } 1 \mathrm{~h} ; \mathrm{THF}}{\stackrel{\text { 2) } \mathrm{R}^{1} \stackrel{\mathrm{O}}{\mathrm{O}}_{\mathrm{R}^{2}} ; 3 \mathrm{~h}}{\text { 3) } \mathrm{NH}_{4} \mathrm{Cl}_{\text {sat. }}}}
$$

Entry

reacting to form the organocerium(III) reagent while with $\mathrm{CeCl}_{3} \cdot \mathrm{H}_{2} \mathrm{O}$ at least 1 equiv. of $\mathrm{RLi}$ is consumed by water (Scheme 11).

$$
\mathrm{LnX}_{3},(\text { thf })_{\mathrm{x}} \stackrel{n-\mathrm{BuLi} ; \mathrm{THF}}{\longrightarrow} n-\mathrm{BuLnLiX}_{3},(\text { thf })_{\mathrm{x}^{\prime}}
$$

Scheme 11.

As a conclusion, all anhydrous lanthanide trihalides prepared are very efficient promoters for the 1,2-addition of organolanthanide(III) reagents to $\alpha, \beta$-unsaturated carbonyl compounds. Moreover, there is no need to use lanthanide trihalides prepared from pure metals since the alloy leads to the formation of very active complexes.

2.3.4. Mukaiyama aldol-type reactions catalysed by anhydrous lanthanide tribromides and triiodides. Mukaiyama aldol-type reactions as well as Michael reactions are fundamental tools for the formation of carbon-carbon bonds in organic chemistry and have been widely developed. Many Lewis acids have been employed either in stoichiometric or in catalytic amounts to carry out these reactions. Especially, Kobayashi et al. have extensively studied the use of rare earth triflates as catalysts. ${ }^{30}$ The first Mukaiyama aldol-type reaction catalysed by lanthanides derivatives was described by Kagan et al. ${ }^{31}$ with the presence of $5 \mathrm{~mol} \%$ of several lanthanide trichlorides. The reactions were rather slow $(12 \mathrm{~h}$ to several days) and yielded either $O$-silylated or desilylated aldols. A few years later, Collin et al. showed the efficiency of lanthanide iodides as catalysts in Mukaiyama aldol-type reaction. ${ }^{32}$ The reactions are very fast $\left(5 \mathrm{~min}\right.$ at $\left.-78^{\circ} \mathrm{C}\right)$ and yields are excellent.

We have studied the reactivity of anhydrous lanthanide tribromides. Their reactivity was assumed to be intermediate between that of lanthanide trichlorides and that of lanthanide triiodides. Some reactions have been carried out between aromatic aldehydes bearing either an electron withdrawing-group or an electron-donating group in various positions and ketene trimethylsilyl methyl acetal (KSA) using $10 \mathrm{~mol} \%$ (with respect to the aldehyde) of anhydrous lanthanide tribromides prepared from mischmetall. The results are presented in Table 12.

The reactions proceed smoothly at room temperature, and reaction times differ according to the group which is on the aromatic ring. For electron-withdrawing groups, the reaction can require up to $20 \mathrm{~h}$, whereas, for electron-donating groups, the reaction is very fast. The expected products were obtained in good yields. In the case of $m$-bromobenzaldehyde, a side-product coming from an Oppenauer-type oxidation of the aldol has been observed. It is noteworthy that reactions performed with anhydrous tribromides prepared from individual metals (samarium, gadolinium, praseodymium and neodymium), led to $\beta$-hydroxy esters in slightly lower yields than with the catalyst prepared from mischmetall. The results are presented in Table 13 .

Mischmetall and neodymium tribromides have been also tested as catalysts in Mukaiyama aldol-type reactions involving an silyl enol ether and aromatic aldehydes. The results are presented in Table 14.

The reactions with $o$-methoxybenzaldehyde and $\beta$-naphtaldehyde are efficiently catalyzed by the tribromides, but with $p$-nitobenzaldehyde the reactions are slow and the silyl enol ether is gradually changed into acetophenone. Finally, we have tested mischmetall triiodide under the conditions used by Collin et al. $\left(-78^{\circ} \mathrm{C}, 5 \mathrm{~min}\right)$ for samarium iodides. ${ }^{32}$ The results are presented in Table 15.

Under these conditions, moderate (entries 3,4 ) to excellent (entries 1,2) yields were obtained.

As a conclusion, this is the first study concerning the reactivity of anhydrous lanthanide tribromides as catalysts. Their reactivity in Mukaiyama aldol-type reaction has been shown to be very good. Moreover, catalysts prepared from mischmetall were found to be more efficient than catalysts prepared from pure metals. This feature is very interesting since the alloy gives access to low-cost catalysts. 
Table 12. Mischmetall tribromide in some Mukaiyama aldol-type reactions

\begin{tabular}{|c|c|c|c|c|c|}
\hline Entry & $\mathrm{R}$ & $\begin{array}{c}\text { KSA } \\
\text { (equiv.) }\end{array}$ & $\begin{array}{l}\text { Reaction time } \\
\text { (h) }\end{array}$ & $\mathrm{Y}$ & $\begin{array}{c}\text { Isolated yields } \\
(\%)^{\mathrm{a}}\end{array}$ \\
\hline 1 & $p$-OMe & 1.1 & 2 & TMS & 78 \\
\hline 2 & $p$-OMe & 1.4 & 2 & TMS & 77 \\
\hline 3 & $p$-OMe & 1.4 & 2 & TMS & $86^{\mathrm{b}}$ \\
\hline 4 & $o$-OMe & 1.1 & 1 & TMS & 76 \\
\hline 5 & $\mathrm{H}$ & 1.4 & 6.5 & $\mathrm{H}$ & 54 \\
\hline 6 & $p-\mathrm{NO}_{2}$ & 1.1 & 4 & $\mathrm{H}$ & 83 \\
\hline 7 & $p-\mathrm{Cl}$ & 1.1 & 20 & $\mathrm{H}$ & 60 \\
\hline 8 & $p-\mathrm{Br}$ & 1.4 & 3 & $\mathrm{H}$ & $34^{\mathrm{c}}$ \\
\hline 9 & $p-\mathrm{CF}_{3}$ & 1.1 & 18 & $\mathrm{H}$ & 68 \\
\hline 10 & $\alpha$-Naphthaldehyde & 1.4 & 3 & $\mathrm{H}$ & 82 \\
\hline
\end{tabular}

${ }^{\mathrm{a}}$ In some cases (entries 5-10) it was easier to purify desilylated products (desilylation with $\mathrm{HCl} 1 \mathrm{M}$ in THF).

b With $20 \mathrm{~mol} \%$ of $\mathrm{LnBr}_{3}$.

${ }^{c}$ A by-product (19\%) arising from an Oppenauer oxidation of the aldol was also obtained.

Table 13. Use of lanthanide tribromides in Mukaiyama aldol-type reactions<smiles>[R]c1ccc(C=O)cc1</smiles>

\begin{tabular}{lllll}
\hline Entry & $\mathrm{R}$ & \multicolumn{1}{c}{$\mathrm{Ln}$} & Reaction time (h) & Isolated yield (\%) \\
\hline 1 & $p$-OMe & $\mathrm{Nd}$ & 1 & 67 \\
2 & $p$-OMe & $\mathrm{Pr}$ & 1 & 63 \\
3 & $p$-OMe & $\mathrm{Sm}$ & 1 & 63 \\
4 & $p-\mathrm{OMe}$ & $\mathrm{Gd}$ & 1 & 63 \\
5 & $p-\mathrm{OMe}$ & $\mathrm{Mischmetall}$ & 1 & 76 \\
6 & $p-\mathrm{CF}_{3}$ & $\mathrm{Nd}$ & 24 & 40 \\
7 & $p-\mathrm{CF}_{3}$ & $\mathrm{Pr}$ & 24 & 40 \\
8 & $p-\mathrm{CF}_{3}$ & $\mathrm{Sm}$ & 24 & 33 \\
9 & $p-\mathrm{CF}_{3}$ & $\mathrm{Gd}$ & 24 & 68 \\
10 & $p-\mathrm{CF}_{3}$ & $\mathrm{Mischmetall}$ & 18 & 67 \\
11 & $p-\mathrm{NO}_{2}$ & $\mathrm{Nd}$ & 24 & 42 \\
12 & $p-\mathrm{NO}_{2}$ & $\mathrm{Pr}$ & 24 & 54 \\
13 & $p-\mathrm{NO}_{2}$ & $\mathrm{Sm}$ & 24 & 50 \\
14 & $p-\mathrm{NO}_{2}$ & $\mathrm{Gd}$ & 4 & 83 \\
15 & $p-\mathrm{NO}_{2}$ & $\mathrm{Mischmetall}$ & 4 & \\
\hline
\end{tabular}

Table 14. Use of lanthanide tribromides (mischmetall and neodymium) in Mukaiyama aldol-type reactions<smiles>[R]c1ccc(C=O)cc1</smiles>

\begin{tabular}{lllll}
\hline Entry & \multicolumn{1}{c}{ Aldehyde } & \multicolumn{1}{c}{ Ln } & Reaction time (h) & Isolated yields $(\%)$ \\
\hline 1 & $o$-Methoxybenzaldehyde & Mischmetall & 3 & 94 \\
2 & $o$-Methoxybenzaldehyde & Nd & 3 & 82 \\
3 & $p$-Nitrobenzaldehyde & Mischmetall & 48 & 44 \\
4 & $p$-Nitrobenzaldehyde & Nd & 48 & 20 \\
5 & $\beta$-Naphtaldehyde & Mischmetall & 24 & 69 \\
\hline
\end{tabular}

\section{Conclusion}

Mischmetall is a very interesting starting material in the field of lanthanide chemistry. Many of its advantages have been highlighted.

(1) Mischmetall has been used as a coreductant for samarium diiodide and, to the best of our knowledge, it is the most widely applicable coreductant known so far. Moreover, the system mischmetall/ $\mathrm{SmI}_{2 \text { (cat.) }}$ can sometimes be more efficient than stoichiometric samarium diiodide. The formation of stable organometallic species have been observed with allylic and benzylic halides at room temperature without any additives.

(2) In Reformatsky-type reaction, mischmetall can be used 
Table 15. Use of mischmetall triiodide in Mukaiyama aldol-type reactions

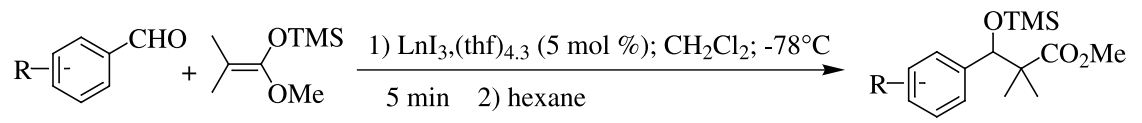

\begin{tabular}{lll}
\hline Entry & $\mathrm{R}$ & Isolated yields $(\%)$ \\
\hline 1 & $p$-OMe & 86 \\
2 & $o-\mathrm{OMe}$ & $90^{\mathrm{a}}$ \\
3 & $p-\mathrm{NO}_{2}$ & 64 \\
4 & $\mathrm{H}$ & 54 \\
\hline
\end{tabular}

a With $10 \mathrm{~mol} \%$ of $\mathrm{LnI}_{3}$.

either as the coreductant of samarium diiodide or as the promoter of the reaction with catalytic amounts of diiodoethane. The system is then more convenient than the Reformatsky-type reaction described by Imamoto et al. mediated by cerium with catalytic amounts of mercury(II) chloride.

(3) A very simple method of metal activation allowed the preparation of anhydrous trichlorides, tribromides and triiodides from mischmetall and also from several pure lanthanide metals. The reactivity of complexes prepared from mischmetall has been further investigated in reactions involving lanthanide halides in stoichiometric amounts (Luche and Imamoto-type reactions) or in catalytic conditions (Mukaiyama aldol-type reaction).

(4) In Luche-Fukuzawa and Imamoto-type reactions, complexes prepared from mischmetall showed an efficiency and selectivity for 1,2-addition to the carbonyl group similar to that of complexes prepared from pure lanthanide metals. Moreover, as they were synthesized in anhydrous conditions, a difference has been observed between their reactivity and those of commercial complexes dried by classical methods. Finally, the catalytic activity of anhydrous lanthanide tribromides has been investigated, showing that catalysts prepared from mischmetall are often more efficient than those made from pure metals.

It has been demonstrated that mischmetall can be used in different ways in the field of organic chemistry but much remains to be explored. Indeed, for a number of years, the chemistry of lanthanide metals has been in constant expansion. Since mischmetall powder can be easily obtained and stored and is much more reactive and cheaper than commercially available lanthanide metals powders, it should become a very useful reagent in organic synthesis.

\section{Experimental}

\subsection{General}

${ }^{1} \mathrm{H}$ and ${ }^{13} \mathrm{C}$ NMR spectra were recorded at 250 and $63 \mathrm{MHz}$ respectively, with a Bruker AC 250 instrument (unless otherwise stated). Chemical shifts are reported in part per million $(\delta)$ downfield from TMS. Infrared (IR) spectra were recorded neat on a FTIR IFS 66 Bruker and are reported in $\mathrm{cm}^{-1}$. Mass spectra (MS) were determined on a GC/MS Ribermag R10-10 instrument. Electronic impact was performed at $70 \mathrm{eV}$. High Resolution Mass Spectra (HRMS) and Electrospray Mass Spectra were performed on a GC/MS Finningan-MAT-95-S. Flash chromatography was performed on silica gel (Merck 230-240 mesh; $0.0040-0.0630 \mathrm{~mm}$ ). All commercially available organic compounds were distilled before use. Lanthanide metals (ingots) were purchased from the Acros Company and mischmetall (cerium mixed metal) from Fluka (about $\$ 60$ per $500 \mathrm{~g}$ ). Mischmetall ingots (about $5 \mathrm{~g}$ ) were easily powered in air with a rasp (caution! mischmetall powder is pyrophoric, sparks can come out from ingot when it is scraped, powder must be collected in a flask filled with argon). The powder was kept under argon in a Schlenck tube, (average molecular weight of mischmetall is 140). Tetrahydrofuran (THF) was distilled under argon from sodium benzophenone ketyl. Samarium diiodide was prepared as previously described. ${ }^{7}$ All reactions were carried out under argon in Schlenck tubes by standard vacuum line techniques. Lanthanide trihalides were stored and handle in a glove box under argon.

\subsection{Catalytic pinacol coupling procedure}

Fast addition. Mischmetall powder $(0.7 \mathrm{~g}, 5 \mathrm{mmol})$ was suspended in THF (2 mL), with Sm $(0.105 \mathrm{~g}, 0.7 \mathrm{mmol})$ and $\mathrm{Br}_{2} \mathrm{CHCHBr}_{2}(1.4 \mathrm{mmol})$ in a Schlenck tube under argon at room temperature for $2 \mathrm{~h}$. Ketone or aldehyde $(4 \mathrm{mmol})$ in THF $(12 \mathrm{~mL})$ was then added to the THF/ $\mathrm{SmBr}_{2} /$ mischmetall suspension. The mixture was then stirred for an additional period of $16 \mathrm{~h}$, diluted with ether, quenched with $\mathrm{HCl}(1 \mathrm{M})$ and stirred for $15 \mathrm{~min}$ to obtain a clear solution, which was extracted with ether. The combined extracts were washed with brine, sodium thiosulfate and brine again. The organic layer was dried with $\mathrm{MgSO}_{4}$, and the solvents were removed under reduced pressure. The crude material was purified by flash chromatography on silica gel.

Slow addition. Mischmetall powder $(0.7 \mathrm{~g}, 5 \mathrm{mmol})$ was suspended in THF $(2 \mathrm{~mL})$, with $\mathrm{Sm}(0.21 \mathrm{~g}, 1.4 \mathrm{mmol})$ and $\mathrm{Br}_{2} \mathrm{CHCHBr}_{2}(0.7 \mathrm{mmol})$ in a Schlenck tube under argon at room temperature for $2 \mathrm{~h}$. THF $(5 \mathrm{~mL})$ was then added. Ketone or aldehyde $(4 \mathrm{mmol})$ in THF $(7 \mathrm{~mL})$ was slowly added to the $\mathrm{THF} / \mathrm{SmBr}_{2} /$ mischmetall suspension over $14 \mathrm{~h}$. The mixture was then stirred for an additional period of $2 \mathrm{~h}$, diluted with ether, quenched with $\mathrm{HCl}(1 \mathrm{M})$ and stirred for 15 min to obtain a clear solution, which was extracted with ether. The combined extracts were washed with brine, sodium thiosulfate and brine again. The organic layer was dried over $\mathrm{MgSO}_{4}$, and the solvents were removed under 
reduced pressure. The crude material was purified by flash chromatography on silica gel.

\subsection{Reformatsky-type reactions mediated by the mischmetall/SmI 2(cat.) $_{\text {system }}$}

Mischmetall powder $(0.7 \mathrm{~g}, 5 \mathrm{mmol})$ was suspended in THF $(7 \mathrm{~mL})$, with $\mathrm{SmI}_{2}(0.7 \mathrm{mmol})$ in a Schlenck tube under argon at room temperature. A solution of an $\alpha$-bromoester ( $4 \mathrm{mmol})$ and ketone $(2 \mathrm{mmol})$ in THF $(7 \mathrm{~mL})$ was slowly added to the THF/SmI $/ 2 /$ mischmetall suspension over $3 \mathrm{~h}$. The mixture was then stirred for an additional period of $0.5 \mathrm{~h}$, diluted with ether, quenched with $\mathrm{HCl}(1 \mathrm{M})$ and stirred for $15 \mathrm{~min}$ to obtain a clear solution, which was extracted with ether. The combined extracts were washed with brine, sodium thiosulfate and brine. The organic layer was dried with $\mathrm{MgSO}_{4}$, and the solvents were removed under reduced pressure. The crude material was purified by flash chromatography on silica gel.

\subsection{Reformatsky-type reaction mediated by mischmetall in the presence of diiodoethane}

A mixture of mischmetall powder $(0.7 \mathrm{~g}, 5 \mathrm{mmol})$ and diiodoethane $(0.197 \mathrm{~g}, 0.7 \mathrm{mmol})$ was vigorously stirred in a Schlenck tube under argon at room temperature for $30 \mathrm{~min}$. THF $(7 \mathrm{~mL})$ was then added. After a short induction period an exothermic reaction occurred. After cooling to room temperature a solution of an $\alpha$-bromoester $(4 \mathrm{mmol})$ and a ketone $(2 \mathrm{mmol})$ in THF $(7 \mathrm{mmol})$ was added. An exothermic reaction occurred again. The mixture was then stirred for an additional period of $15 \mathrm{~min}$ and treated as described above. Similar procedures were used with $\mathrm{I}_{2}$ and 1,2-dibromoethane.

\subsection{Preparation of anhydrous lanthanide trichlorides $(\mathbf{L n}=$ mischmetall, Nd, Pr, Sm, Gd)}

Metal powder $(10 \mathrm{mmol})$ was vigorously stirred in a Schlenck tube under argon at room temperature for $30 \mathrm{~min}$. A solution of hexachloroethane $(4.26 \mathrm{~g}, 18 \mathrm{mmol})$ in THF was slowly added over $30 \mathrm{~min}$. An exothermic reaction occurred. The mixture was stirred for an additional period of $4 \mathrm{~h}$ at room temperature (to make sure that all the metal powder is consumed, it can be refluxed for $12 \mathrm{~h}$ ). Hexane $(10 \mathrm{~mL})$ was added to the cooled mixture, which was allowed to settle. The supernatant solution was then removed. Precipitate $\left.\left(\mathrm{LnCl}_{3} \text {, (thf }\right)_{x}\right)$ was washed three times with hexane $(3 \times 25 \mathrm{~mL})$. Remaining solvents were removed under reduced pressure $\left(10^{-1}\right.$ Torr $)$ and heating $\left(60^{\circ} \mathrm{C}\right)$. Products were kept and weighed in a glove box.

\subsection{Preparation of anhydrous lanthanide tribromides $(\mathbf{L n}=$ mischmetall, Nd, Pr, Sm, Gd)}

The same procedure was used.

\subsection{Preparation of anhydrous lanthanide triiodides (Ln=mischmetall, La, Nd, Pr, Sm, Gd)}

The same procedure was used, except that the mixture was simply stirred for $12 \mathrm{~h}$ at room temperature.
Titrations were performed on the solids $\left(\operatorname{LnX}_{3},(\text { thf })_{x}\right)$ as described in Ref. 13. Numbers of coordinated thf were established on weighed aliquots from determinations of halide and lanthanide contents.

\subsection{Luche-Fukuzawa-type reductions of $\alpha, \beta$ - unsaturated carbonyl compounds}

Anhydrous $\mathrm{LnCl}_{3},(\text { thf })_{1.8} \quad(\mathrm{Ln}=$ mischmetall $)$ powder $(0.376 \mathrm{~g}, 1 \mathrm{mmol})$ and a carbonyl compound $(1 \mathrm{mmol})$ in THF (3 mL) were stirred in a Schlenck tube under argon at room temperature for $10 \mathrm{~min}$. A solution of $\mathrm{LiAlH}_{4}$ $(0.5 \mathrm{mmol}$ for ketones and aldehydes, $1 \mathrm{mmol}$ for acids and esters) in THF ( $5 \mathrm{~mL})$ was then added. The mixture was stirred for $15 \mathrm{~min}$, quenched with $\mathrm{HCl}(0.1 \mathrm{M}$, until $\mathrm{pH}=7)$ and extracted with ether. The combined extracts were washed with brine, dried with $\mathrm{MgSO}_{4}$ and the solvents were removed under reduced pressure. The crude material was purified by flash chromatography on silica gel.

\subsection{Imamoto-type reactions}

Anhydrous mischmetall trihalide powder $(1.3 \mathrm{mmol})$ in THF $(2 \mathrm{~mL})$ was stirred in a Schlenck tube under argon at room temperature for $1 \mathrm{~h}$, then cooled at $-78^{\circ} \mathrm{C}$. A solution of $n$-butylithium $(1.3 \mathrm{mmol})$ in hexane $(2 \mathrm{~mL})$ was added and stirring was maintained for an additional period of $0.5 \mathrm{~h}$. A carbonyl compound $(1 \mathrm{mmol})$ in THF $(5 \mathrm{~mL})$ was then added. The mixture was stirred for $3 \mathrm{~h}$ at $-78^{\circ} \mathrm{C}$, then hydrolysed with saturated ammonium chloride and extracted with $\mathrm{CH}_{2} \mathrm{Cl}_{2}$. The combined extracts were dried with $\mathrm{MgSO}_{4}$ and the solvents were removed under reduced pressure. The crude material was purified by flash chromatography on silica gel.

\subsection{Mukaiyama aldol reactions}

Catalysed by anhydrous lanthanide tribromides. Anhydrous lanthanide tribromide powder $(0.1 \mathrm{mmol})$ in $\mathrm{CH}_{2} \mathrm{Cl}_{2}$ $(10 \mathrm{~mL})$ was stirred in a Schlenck tube under argon at room temperature for $10 \mathrm{~min}$. Reagents were then added, first an aldehyde $(1 \mathrm{mmol})$ then KSA $(1.1$ or $1.4 \mathrm{mmol})$. Stirring was continued for $1-24 \mathrm{~h}$, with GC monitoring. The mixture was treated with hexane $(10 \mathrm{~mL})$. Lanthanide salts precipitate was then removed by filtration. Solvents were removed under reduced pressure. The crude material (silylated products) was purified by flash chromatography on silica gel.

Desilylation was performed with $\mathrm{HCl} 1 \mathrm{M}(3 \mathrm{~mL})$ in THF ( $3 \mathrm{~mL})$. The mixture was stirred for $2 \mathrm{~h}$, then extracted with dichloromethane. The combined extracts were dried with $\mathrm{MgSO}_{4}$ and the solvents were removed under reduced pressure. The crude material was purified by flash chromatography on silica gel.

Catalysed by anhydrous lanthanide triiodides. The same procedure was employed except that $0.05 \mathrm{mmol}$ of lanthanide salt was used and the reactions were performed at $-78^{\circ} \mathrm{C}$ within $5 \mathrm{~min}$.

All the compounds have been previously prepared and characterised. Some selected data are indicated below. 
4.10.1. Bicyclobutyl-1,1'-diol (1). Purification. Column chromatography on silica gel (pentane/ethyl acetate 60:40) white solid, (66\% yield). ${ }^{1} \mathrm{H}$ NMR $\left(\mathrm{CDCl}_{3}\right) \delta(\mathrm{ppm}): 2.14$ (s, $2 \mathrm{H}, 2 \mathrm{OH}) ; 2.00(\mathrm{~m}, 6 \mathrm{H}) ; 1.63(\mathrm{~m}, 2 \mathrm{H}) .{ }^{13} \mathrm{C} \mathrm{NMR}\left(\mathrm{CDCl}_{3}\right) \delta$ (ppm): 78.4; 30.5; 12.8. HRMS $(\mathrm{m} / \mathrm{z})$ : calcd for $\mathrm{C}_{8} \mathrm{H}_{12} \mathrm{O}$ $\left(\mathrm{M}^{+}-\mathrm{H}_{2} \mathrm{O}\right)$, 124.0888; found, 124.0885. Anal. calcd for $\mathrm{C}_{8} \mathrm{H}_{14} \mathrm{O}_{2}$ : C, 67.57; H, 9.92; O, 22.50. Found: C, 67.31; H, 9.91. FTIR $\left(\mathrm{CaF}_{2} / \mathrm{CCl}_{4}\right) \nu_{\max }: 3625 ; 3573 ; 2989 ; 2948$; $2870 ; 2841 ; 1458 ; 1417 ; 1355 ; 1301 ; 1251 ; 1151 ; 1125$; 1041 .

4.10.2. 2,2,5,5-Tetramethyl-hexane-3,4-diol (2). Purification. Column chromatography on silica gel (pentane/ethyl acetate 90:10) white solid, (63\% yield). dl/meso 100:0. ${ }^{1} \mathrm{H}$ NMR $\left(\mathrm{CDCl}_{3}\right) \delta(\mathrm{ppm}): 3.33\left(\mathrm{~d}, J=6.7 \mathrm{~Hz}, 2 \mathrm{H}, \mathrm{C}(3) \mathrm{H}_{2}\right.$, $\left.\mathrm{C}(4) \mathrm{H}_{2}\right) ; 2.34(\mathrm{~d}, J=6.7 \mathrm{~Hz}, 2 \mathrm{H}, 2 \mathrm{OH}) ; 0.90\left(\mathrm{~s}, 18 \mathrm{H}, 9 \mathrm{CH}_{3}\right)$. ${ }^{13} \mathrm{C} \mathrm{NMR}\left(\mathrm{CDCl}_{3}\right) \delta(\mathrm{ppm}): 74.8(\mathrm{C}(3), \mathrm{C}(4)) ; 35.2(\mathrm{C}(2)$, $\mathrm{C}(5)) ; 25.8\left(\mathrm{CH}_{3}\right)$. HRMS $(\mathrm{m} / \mathrm{z})$ : calcd for $\mathrm{C}_{10} \mathrm{H}_{22} \mathrm{O}_{2}\left(\mathrm{M}^{+}\right)$, 174.1620; found, 174.1620. FTIR $\left(\mathrm{CaF}_{2} / \mathrm{CCl}_{4}\right) \nu_{\max }$ : 3642; $3543 ; 2961 ; 2909 ; 2870 ; 1477 ; 1465 ; 1394 ; 1365 ; 1240$; $1181 ; 1088 ; 1060 ; 1009$.

4.10.3. cis-1,2-Diphenylcyclopentane-1,2-diol (3). Purification. Column chromatography on silica gel (pentane/ethyl acetate 80:20), white solid, (70\% yield). dl/meso $0: 100 .{ }^{1} \mathrm{H}$ NMR $\left(\mathrm{CDCl}_{3}\right) \delta(\mathrm{ppm}): 7.05(\mathrm{~m}, 10 \mathrm{H}, 2 \mathrm{Ph}) ; 3.00(\mathrm{~s}, 2 \mathrm{H}$, $2 \mathrm{OH}) ; 2.58(\mathrm{~m}, 2 \mathrm{H}) ; 2.45-2.00(\mathrm{~m}, 4 \mathrm{H}) .{ }^{13} \mathrm{C} \mathrm{NMR}\left(\mathrm{CDCl}_{3}\right)$ $\delta$ (ppm): 142.4; 127.2; 126.9; 126.2; 85.7 (C(1), C(2)); 36.9; 20.0. GC/Ms: $m / z(\%)=55$ (19); 77 (27); 104 (50); 105 (100); 120 (19); 133 (13); 218 (6); 236 (2); 254 (4). HRMS $(\mathrm{m} / \mathrm{z})$ : calcd for $\mathrm{C}_{17} \mathrm{H}_{18} \mathrm{O}_{2}\left(\mathrm{M}^{+}\right), 254.1307$; found, 254.1310. FTIR $\left(\mathrm{CaF}_{2} / \mathrm{CCl}_{4}\right) \quad \nu_{\max }: 3614 ; 3567 ; 3093$; $3064 ; 3041 ; 3029 ; 2953 ; 2879 ; 1497 ; 1369 ; 1195 ; 1124$; $1065 ; 1035$.

4.10.4. Ethyl 2-(2-hydroxyindan-2-yl)-butanoate (4). Purification. Column chromatography on silica gel (heptane/ethyl acetate 80:20), white solid, (54\% yield). ${ }^{1} \mathrm{H}$ NMR $\left(\mathrm{CDCl}_{3}\right) \delta(\mathrm{ppm}): 7.17\left(4 \mathrm{H}, \mathrm{m}, \mathrm{H}_{\mathrm{ar}}\right) ; 4.24(2 \mathrm{H}, \mathrm{q}$, $\left.\mathrm{O}-\mathrm{CH}_{2}-\mathrm{CH}_{3}, \quad J_{\mathrm{CH}_{2}-\mathrm{CH}_{3}}=7.3 \mathrm{~Hz}\right) ; 3.27(1 \mathrm{H}, \quad$ s broad, $\left.\mathrm{C}\left(2^{\prime}\right) \mathrm{OH}\right) ; 3.00\left(4 \mathrm{H}, \mathrm{m}, \mathrm{C}\left(1^{\prime}\right) \mathrm{H}_{2}, \mathrm{C}\left(3^{\prime}\right) \mathrm{H}_{2}\right) ; 2.55(1 \mathrm{H}, \mathrm{dd}$, $\left.\mathrm{C}(2) \mathrm{H}, \quad J_{2-\mathrm{Ha}}=10.8 \mathrm{~Hz}, \quad J_{2-\mathrm{Hb}}=3.9 \mathrm{~Hz}\right) ; \quad 1.86 \quad(2 \mathrm{H}, \quad \mathrm{m}$, $\left.\mathrm{C}(3) \mathrm{H}_{\mathrm{a}} \mathrm{H}_{\mathrm{b}}\right) ; 1.32\left(3 \mathrm{H}, \mathrm{t}, \mathrm{O}-\mathrm{CH}_{2}-\mathrm{CH}_{3}, \mathrm{~J}_{\mathrm{CH}_{3}}-\mathrm{CH}_{2}=7.3 \mathrm{~Hz}\right)$; $0.98\left(3 \mathrm{H}, \mathrm{t}, \mathrm{C}(4) \mathrm{H}_{3}, J_{4-3}=7.6 \mathrm{~Hz}\right) .{ }^{13} \mathrm{C} \mathrm{NMR}\left(\mathrm{CDCl}_{3}\right) \delta$ (ppm): $175.8(\mathrm{C}(1)) ; 140.7$ and $140.5\left(\mathrm{C}\left(3^{\prime} \mathrm{a}\right), \mathrm{C}\left(7^{\prime} \mathrm{a}\right)\right) ; 126.4$ $\left(\mathrm{C}\left(4^{\prime}\right), \mathrm{C}\left(7^{\prime}\right)\right) ; 124.6\left(\mathrm{C}\left(5^{\prime}\right), \mathrm{C}\left(6^{\prime}\right)\right) ; 82.0\left(\mathrm{C}\left(2^{\prime}\right)\right) ; 60.4$ $\left(\mathrm{O}-\mathrm{CH}_{2}-\mathrm{CH}_{3}\right) ; 55.5(\mathrm{C}(2)) ; 46.5$ and $44.6\left(\mathrm{C}\left(1^{\prime}\right), \mathrm{C}\left(3^{\prime}\right)\right)$; $21.4(\mathrm{C}(3)) ; 14.1\left(\mathrm{O}-\mathrm{CH}_{2}-\mathrm{CH}_{3}\right) ; 12.2(\mathrm{C}(4))$. GC/MS m/z (\% base peak): $248(1) ; 230(21) ; 157(21) ; 156(8) ; 143(8) ; 133$ (10); 132 (31); $129(10) ; 117(11) ; 116(22) ; 115(27) ; 105(57)$; 104 (100); 103 (47); 101 (22); 91 (18); 88 (12); 79 (14); 78 (24); 77 (28); 73 (35); 71 (13); 70 (12); 55 (17); 43 (24); 41 (14); 39 (11). FTIR $\left(\mathrm{CaF}_{2} /\right.$ nujol $) \nu_{\max }: 3520 ; 1715 ; 1348$; $1318 ; 1291 ; 1262 ; 1226 ; 1213 ; 1180 ; 1154 ; 1129 ; 1099 ; 1080$.

4.10.5. (E)-3-Methyl-1-(2,6,6-trimethylcyclohex-2-enyl)hept-1-en-3-ol (5). Purification. Column chromatography on silica gel (heptane/ethyl acetate 95:5), colourless oil, (96\% yield). ${ }^{1} \mathrm{H} \mathrm{NMR}\left(\mathrm{CDCl}_{3}\right) \delta(\mathrm{ppm}): 5.37(3 \mathrm{H}, \mathrm{m}$, $\left.\mathrm{C}(1) \mathrm{H}, \mathrm{C}(2) \mathrm{H}, \mathrm{C}\left(3^{\prime}\right) \mathrm{H}\right) ; 2.02\left(1 \mathrm{H}, \mathrm{d}, \mathrm{C}\left(1^{\prime}\right) \mathrm{H}, J_{1^{\prime}-1}=8.8 \mathrm{~Hz}\right)$; $1.90\left(2 \mathrm{H}, \mathrm{m}, \mathrm{C}\left(4^{\prime}\right) \mathrm{H}_{2}\right) ; 1.63-1.04\left(9 \mathrm{H}, \mathrm{m}, \mathrm{C}(3) \mathrm{OH}, \mathrm{C}(4) \mathrm{H}_{2}\right.$, $\left.\mathrm{C}(5) \mathrm{H}_{2}, \mathrm{C}(6) \mathrm{H}_{2}, \mathrm{C}\left(5^{\prime}\right) \mathrm{H}_{2}\right) ; 1.51\left(3 \mathrm{H}, \mathrm{s}, \mathrm{C}\left(2^{\prime}\right)-\mathrm{CH}_{3}\right) ; 1.20$ $\left(3 \mathrm{H}, \mathrm{s}, \mathrm{C}(3)-\mathrm{CH}_{3}\right) ; 0.81\left(6 \mathrm{H}, \mathrm{s}, \mathrm{C}\left(6^{\prime}\right)-\left(\mathrm{CH}_{3}\right)_{2}\right) ; 0.74(3 \mathrm{H}$, $\left.\mathrm{m}, \mathrm{C}(7)-\mathrm{CH}_{3}\right) .{ }^{13} \mathrm{C} \mathrm{NMR}\left(\mathrm{CDCl}_{3}\right) \delta(\mathrm{ppm}): 137.9 ; 133.3$ $\left(\mathrm{C}\left(2^{\prime}\right)\right) ; 127.3 ; 119.2 ; 72.2(\mathrm{C}(3)) ; 53.2\left(\mathrm{C}\left(1^{\prime}\right)\right) ; 41.7\left(\mathrm{C}\left(4^{\prime}\right)\right)$; $31.0\left(\mathrm{C}\left(6^{\prime}\right)\right) ; 30.7 ; 27.4 ; 26.7 ; 26.1 ; 25.5 ; 22.2(\mathrm{C}(5), \mathrm{C}(6))$; $21.9\left(\mathrm{C}\left(2^{\prime}\right)-\mathrm{CH}_{3}\right) ; 13.2(\mathrm{C}(7))$. GC/MS $\mathrm{m} / z$ (\% base peak): 232 (9); 217 (2); 194 (14); 193 (23); 176 (25); 161 (8); 151 (10); 147 (10); 137 (22); 133 (26); 123 (27); 119 (41); 109 (22); 105 (29); 93 (28); 91 (36); 79 (20); 71 (19); 55 (50); 43 (100); 41 (82). FTIR (NaCl/liquid film) $\nu_{\max }: 3401 ; 3025$; $2961 ; 2929 ; 2853 ; 1732 ; 1456 ; 1377 ; 1363 ; 1298 ; 1255$; 1129; 976; 936; 826; 794.

4.10.6. (E)-3-Methyl-1-(2,6,6-trimethylcyclohex-1-enyl)hept-1-en-3-ol (6). Purification. Column chromatography on silica gel (heptane/ethyl acetate 90:10), colourless oil, (95\% yield). ${ }^{1} \mathrm{H}$ NMR $\left(\mathrm{CDCl}_{3}\right) \delta(\mathrm{ppm}): 5.95(1 \mathrm{H}, \mathrm{d}, \mathrm{C}(1) \mathrm{H}$, $\left.J_{1-2}=16.1 \mathrm{~Hz}\right) ; 5.40\left(1 \mathrm{H}, \mathrm{d}, \mathrm{C}(2) \mathrm{H}, J_{2-1}=16.1 \mathrm{~Hz}\right) ; 1.90$ $\left(2 \mathrm{H}, \quad \mathrm{t}, \mathrm{C}\left(3^{\prime}\right) \mathrm{H}_{2}, \quad J_{3^{\prime}-4^{\prime}}=6.6 \mathrm{~Hz}\right) ; 1.61-1.16(11 \mathrm{H}, \mathrm{m}$, $\left.\mathrm{C}(3) \mathrm{OH}, \mathrm{C}(4) \mathrm{H}_{2}, \mathrm{C}(5) \mathrm{H}_{2}, \mathrm{C}(6) \mathrm{H}_{2}, \mathrm{C}\left(4^{\prime}\right) \mathrm{H}_{2}, \mathrm{C}\left(5^{\prime}\right) \mathrm{H}_{2}\right) ; 1.58$ $\left(3 \mathrm{H}, \mathrm{s}, \mathrm{C}\left(2^{\prime}\right)-\mathrm{CH}_{3}\right) ; 1.24\left(3 \mathrm{H}, \mathrm{s}, \mathrm{C}(3)-\mathrm{CH}_{3}\right) ; 0.91(6 \mathrm{H}, \mathrm{s}$, $\left.\mathrm{C}\left(6^{\prime}\right)-\left(\mathrm{CH}_{3}\right)_{2}\right) ; 0.83\left(3 \mathrm{H}, \mathrm{t}, \mathrm{C}(7) \mathrm{H}_{3}, J_{7-6}=7.1 \mathrm{~Hz}\right) .{ }^{13} \mathrm{C}$ NMR $\left(\mathrm{CDCl}_{3}\right) \delta(\mathrm{ppm}): 140.8(\mathrm{C}(2)) ; 137.2\left(\mathrm{C}\left(1^{\prime}\right)\right) ; 128.1$ $\left(\mathrm{C}\left(2^{\prime}\right)\right) ; 124.8(\mathrm{C}(1)) ; 73.5(\mathrm{C}(3)) ; 42.7\left(\mathrm{C}\left(3^{\prime}\right)\right)$; $39.5(\mathrm{C}(4))$; $34.1\left(\mathrm{C}\left(6^{\prime}\right)\right) ; 32.8 ; 28.9\left(\mathrm{C}\left(6^{\prime}\right)\left(C_{3}\right)_{2}\right) ; 28.5\left(\mathrm{C}(3)-C \mathrm{H}_{3}\right)$; $26.6 ; 23.3(\mathrm{C}(5)) ; 21.5\left(\mathrm{C}\left(2^{\prime}\right)-\mathrm{CH}_{3}\right) ; 19.4(\mathrm{C}(6)) ; 14.2$ (C(7)). GC/MS m/z (\% base peak): 233 (18); 232 (93); 217 (40); 203 (5); 189 (22); 175 (30); 161 (27); 147 (55); 133 (36); 121 (30); 119 (100); 107 (26); 105 (65); 95 (19); 93 (18); 91 (34); 81 (14); 77 (14); 69 (18); 55 (33); 43 (23); 41 (51). FTIR (NaCl/liquid film) $\nu_{\max }: 3401 ; 2953 ; 2929 ; 2860$; 1714 ; 1653 ; 1458; 1377; 1360; 1260; 1124; 1041; 1030; 976; $908 ; 804$.

\section{Acknowledgements}

We thank the University of Paris-Sud and the CNRS for their financial support.

\section{References}

1. Namy, J. L.; Girard, P.; Kagan, H. B. New J. Chem. 1977, 1, 5-7.

2. Corey, E. J.; Zheng, G. Z. Tetrahedron Lett. 1997, 38, 2045-2048.

3. Nomura, R.; Matsumo, T.; Endo, T. J. Am. Chem. Soc. 1996, 118, 11666-11667.

4. (a) Fukuzawa, S.; Sumimoto, N.; Fujinami, T.; Sakai, S. J. Org. Chem. 1990, 55, 1628-1631. (b) Fukuzawa, S.; Fujinami, T.; Sakai, S. J. Chem. Soc. Chem. Commun. 1986, 475-476.

5. Di Scala, A.; Garbacia, S.; Hélion, F.; Lannou, M. I.; Namy, J. L. Eur. J. Org. Chem. 2002, 2989-2995.

6. Souppe, J.; Namy, J. L.; Kagan, H. B. Tetrahedron Lett. 1982, 23, 3497-3500.

7. Girard, P.; Namy, J. L.; Kagan, H. B. J. Am. Chem. Soc. 1980, 102, 2693-2698.

8. Lannou, M. I.; Hélion, F.; Namy, J. L. Tetrahedron Lett. 2002, 43, 8007-8010.

9. Machrouhi, F.; Hamann, B.; Namy, J. L.; Kagan, H. B. Synlett 1996, 633-634.

10. Namy, J. L.; Souppe, J.; Kagan, H. B. Tetrahedron Lett. 1983, $24,765-766$. 
11. Hélion, F.; Namy, J. L. J. Org. Chem. 1999, 64, 2944-2946.

12. Lebrun, A.; Rantze, E.; Namy, J. L.; Kagan, H. B. New J. Chem. 1995, 19, 699-705.

13. Namy, J. L.; Girard, P.; Kagan, H. B.; Caro, P. E. New J. Chem. 1981, 5, 479-484.

14. Fukuzawa, S.; Matsuzawa, H.; Yoshimitsu, S. J. Org. Chem. 2000, 65, 1702-1706.

15. (a) Molander, G. A.; Etter, J. B.; Harring, L. S.; Thorel, J. P. J. Am. Chem. Soc. 1991, 113, 8036-8044. (b) Molander, G. A.; Brown, G. A.; Storch de Garcia, I. J. Org. Chem. 2002, 67, 3453-3463.

16. Inanaga, J.; Yokoyama, Y.; Handa, Y.; Yamaguchi, M. Tetrahedron Lett. 1991, 32, 6371-6374.

17. Newman, M. S.; Evans, F. J., Jr. J. Am. Chem. Soc. 1955, 77, 946-947.

18. Utimoto, K.; Takai, T.; Matsubara, S. Bull. Soc. Chim. Fr. 1997, 134, 365-369.

19. Fürstner, A. Synthesis 1989, 571-590.

20. Chao, L. C.; Rieke, R. D. J. Org. Chem. 1975, 40, 2253-2255.

21. Kagoshima, H.; Hashimoto, Y.; Oguro, D.; Saigo, K. J. Org. Chem. 1998, 63, 691-697.

22. Imamoto, T.; Kusumoto, T.; Tawarayama, Y.; Sugiura, Y.; Mita, T.; Hatanaka, Y.; Yokoyama, M. J. Org. Chem. 1984, 49, 3904-3912.

23. Nakanishi, A.; Fukuzawa, S. I.; Fujinami, T.; Sakai, S. Chem. Express 1986, 1, 275-278.
24. Deacon, G. B.; Feng, T.; Nickel, S.; Skelton, B. W.; White, A. H. J. Chem. Soc., Chem. Commun. 1993, 1328-1329.

25. Hitchcock, P. B.; Lappert, M. F.; Prashar, S. J. Organomet. Chem. 2000, 613, 105-110.

26. (a) Hazin, P. N.; Human, J. C.; Bruno, J. V. Organometallics 1987, 6, 23-27. (b) Giuseppone, N. PhD Thesis, University of Paris-Sud, 2000.

27. Fukuzawa, S. I.; Fujinami, T.; Yamaguchi, S.; Sakai, S. J. Chem. Soc., Perkin Trans. 1 1986, 1929-1932.

28. Evans, W. J.; Feldman, J. D.; Ziller, J. W. J. Am. Chem. Soc. 1996, 118, 4581-4584.

29. (a) Imamoto, T.; Kusumoto, T.; Yokoyama, M. J. Chem. Soc., Chem. Commun. 1982, 1042-1044. (b) Imamoto, T.; Takiyama, N.; Nakamura, K.; Hatajima, T.; Kamiya, Y. J. Am. Chem. Soc. 1989, 111, 4392-4398.

30. (a) Kobayashi, S. Chem. Lett. 1991, 2087-2089. (b) Kobayashi, S.; Hachiya, I. Tetrahedron Lett. 1992, 33, 1625-1628. (c) Kobayashi, S.; Sugiura, M.; Kitagawa, H.; Lam, W. W. L. Chem. Rev. 2002, 102, 2227-2302.

31. Vougioukas, A. E.; Kagan, H. B. Tetrahedron Lett. 1987, 28, 5513-5516.

32. (a) Van de Weghe, P.; Collin, J. Tetrahedron Lett. 1993, 35, 3881-3884. (b) Giuseppone, N.; Van de Weghe, P.; Mellah, M.; Collin, J. Tetrahedron 1998, 54, 13129-13148. 